\title{
/ HOW DOES ACCESS TO PUBLIC TRANSIT AFFECT THE QUALITY OF LIFE OF SENIORS OVER 75 IN OTTAWA? A QUALITATIVE ANALYSIS
}

\author{
By \\ Kathleen Mullen, B.E.S (Hons.) \\ A thesis submitted to the Faculty of Graduate Studies and Research in partial fulfillment \\ of the requirements for the degree of Master of Arts \\ Department of Geography and Environmental Studies \\ Carleton University \\ Ottawa, Ontario \\ (C) September 21, 2005
}




\section{ABSTRACT}

The growing aging population in Ottawa presents serious challenges about the way we plan the future of our city. Seniors are likely to age in place in suburban areas, making the provision of transit service in these areas important but problematic.

Furthermore, the literature makes two assumptions about the travel patterns of seniors: first, they will drive as long as possible, often well into their eighties and beyond; and second, the growing aging population will result in an increased demand for public transit service. These assumptions are explored using qualitative methods in the form of focus groups and interviews, asking seniors to evaluate their need for accessible public transit, their likelihood of using transit if they lose their license and the connection they see between the availability of accessible public transit and their ability to maintain a high quality of life.

The results demonstrate that seniors do not plan for the mobility challenges inherent in life after driving. Access to and availability of public transit influences the social activities they participate in, decreases isolation and enables independence amongst non-driving seniors interviewed, qualities all linked to improvements in overall quality of life. Non-drivers prefer specialized door-to-door service to conventional transit, pointing toward the need to educate seniors about accessibility improvements made to conventional transit infrastructure. 


\section{ACKNOWLEDGEMENTS}

To begin, I wish to thank both Fran Klodawsky and Iain Wallace for their support throughout my two years spent at Carleton. The patience, understanding and kindness they have shown me throughout this process have allowed me to reach a goal I never expected to achieve.

Thank you to Hazel Anderson for your advice, attention to details, enthusiasm and chocolates over the past two years. You make everything easier! And to Laura Cain, thank you for always listening and cheering me on.

Finally, to Cory Hamelin - I couldn't have done this without you. You have encouraged me, kept me grounded, offered advice and understood me better than anyone else could have during this process, and for that I am grateful. 


\section{TABLE OF CONTENTS}

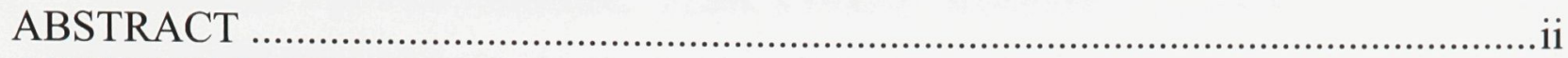

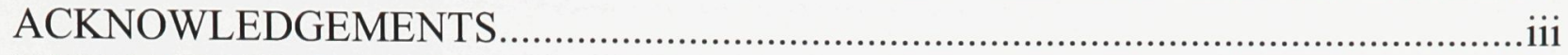

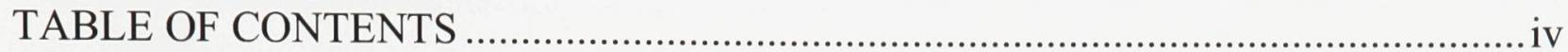

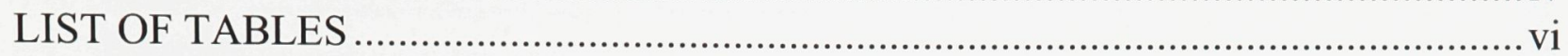

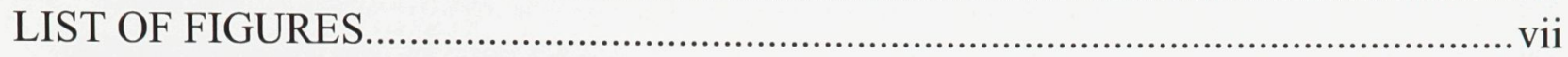

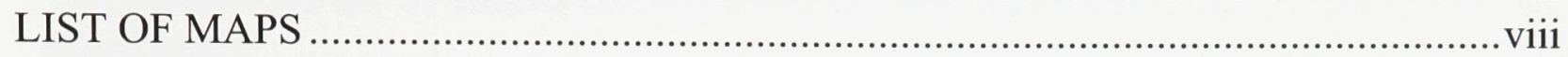

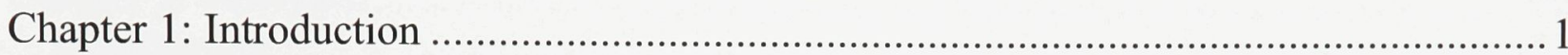

Chapter 2: Transportation and Planning in the Auto-Dominant City ............................... 7

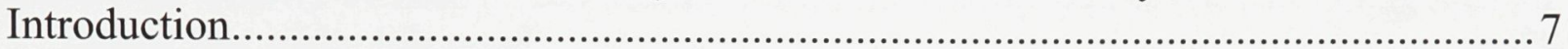

The transportation/land-use problem and aging-in-place _........................................ 9

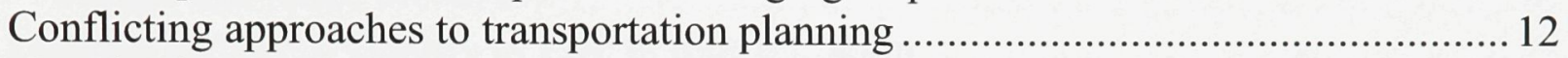

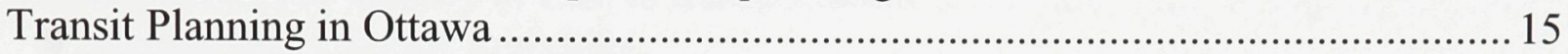

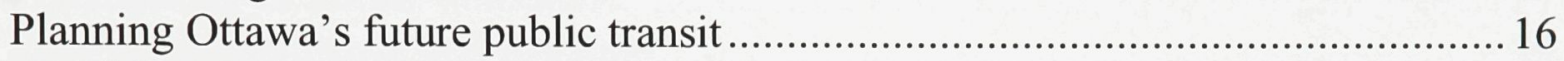

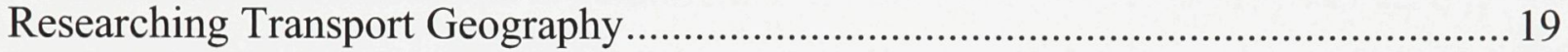

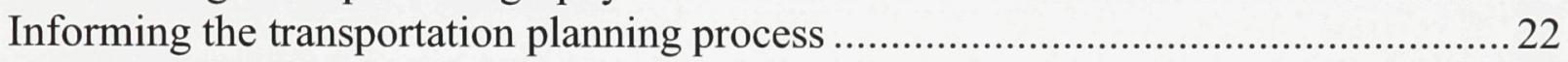

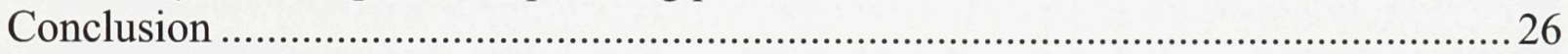

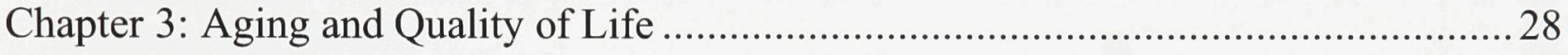

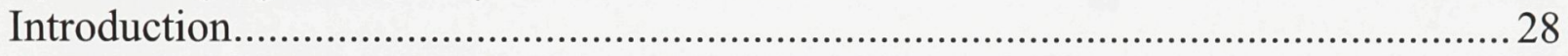

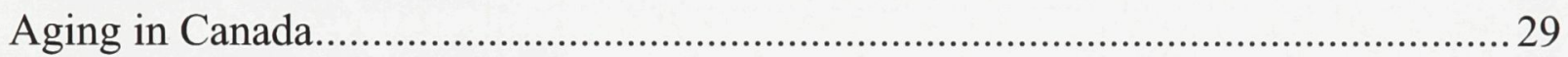

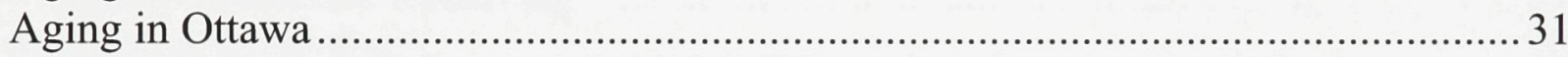

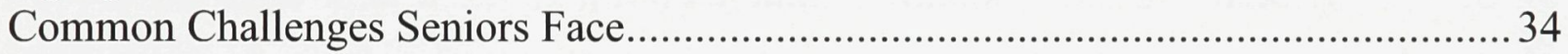

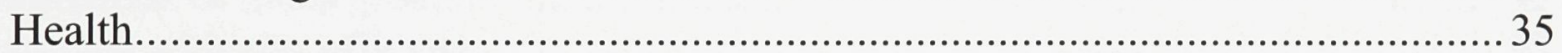

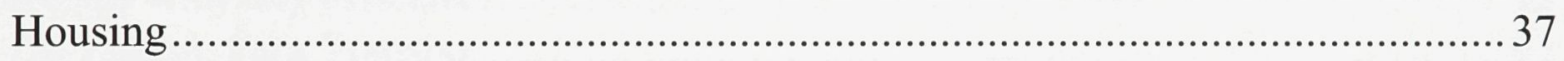

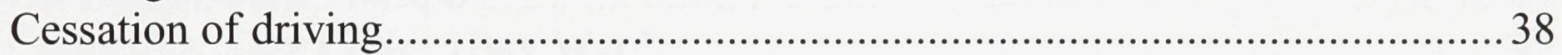

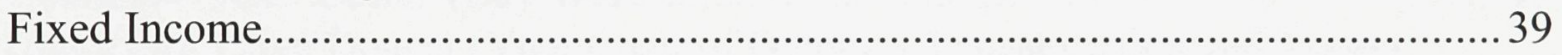

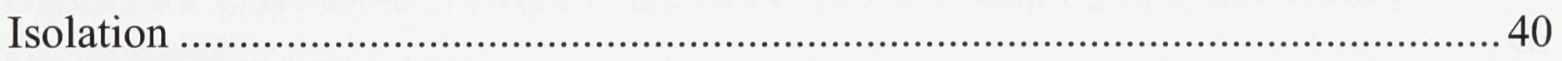

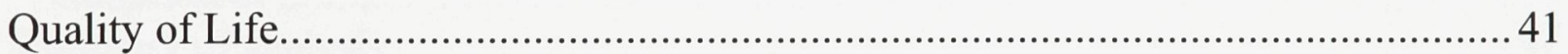

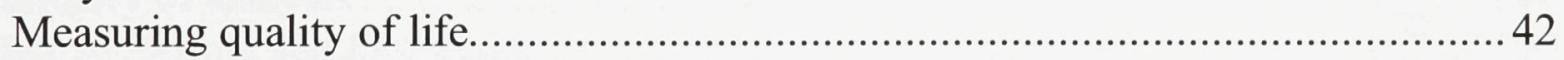

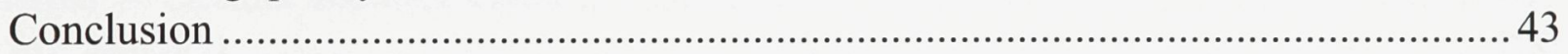

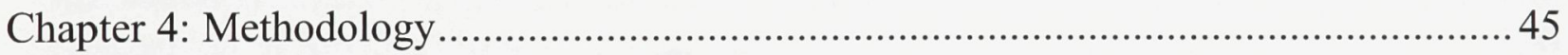

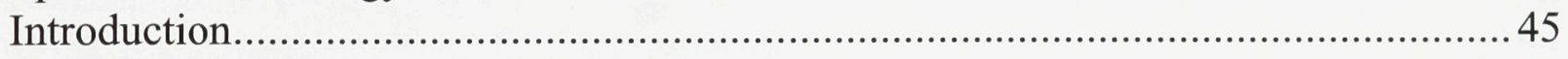

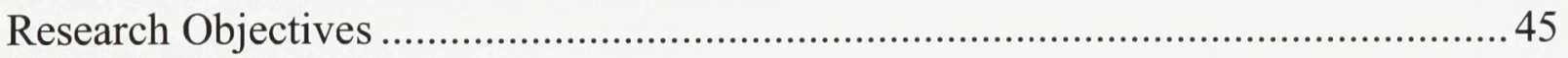

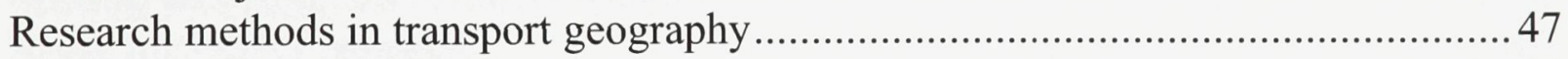

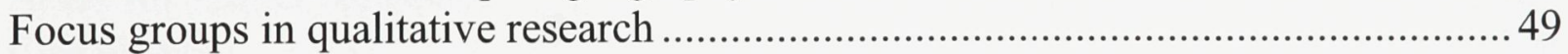

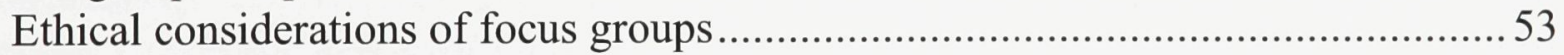

Drawbacks of focus group methodology .......................................................... 54

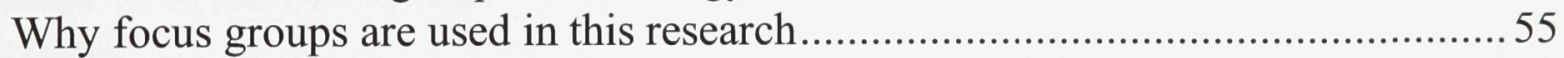

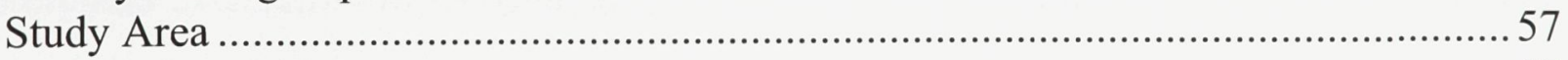

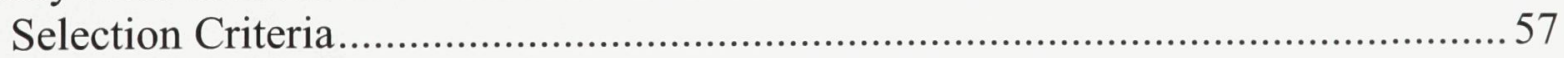

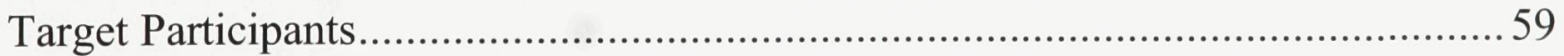

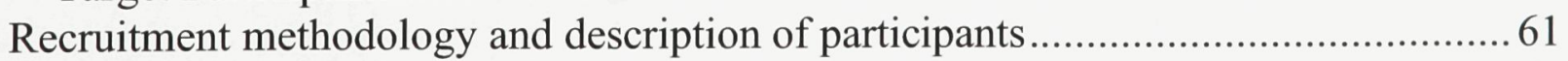

Soloway Jewish Community Centre, August 9, 2004 .......................................... 64 
Sterling Place Retirement Community, August 12, 2004_......................................64 64

Somerset Towers Complex, August 25, 2004.....................................................65

Participant's private residence, 'Frank's House' September 15, 2004 ...................66 66

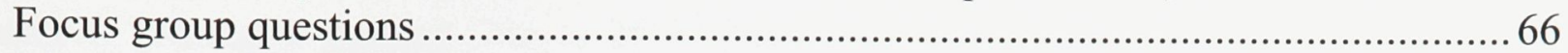

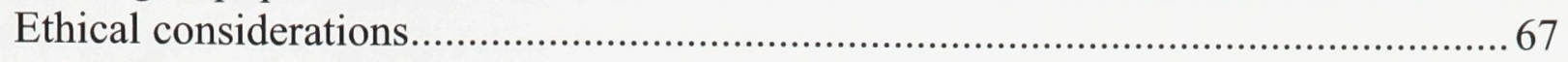

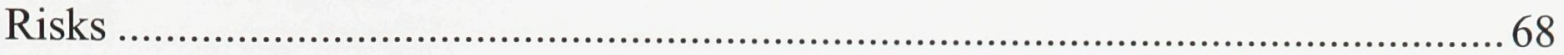

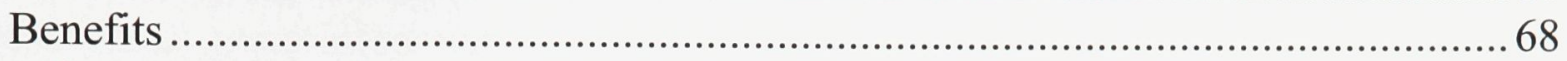

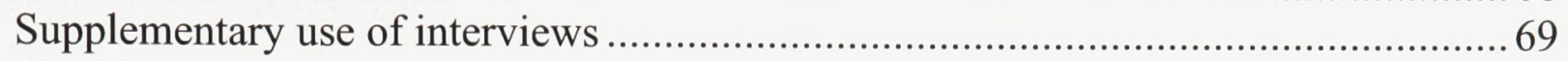

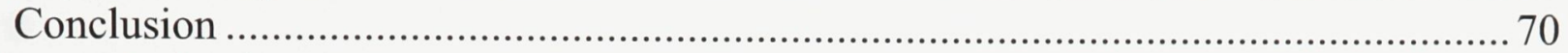

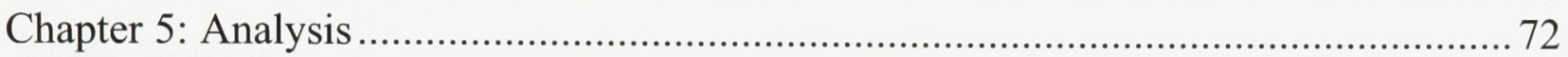

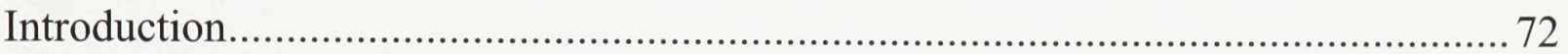

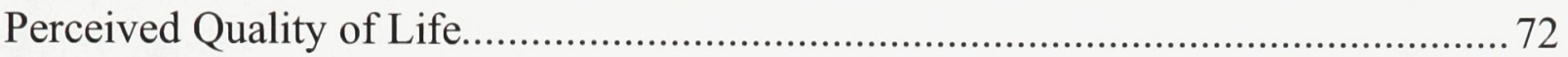

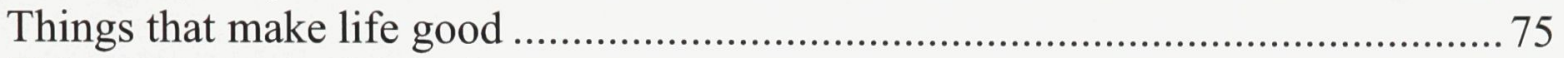

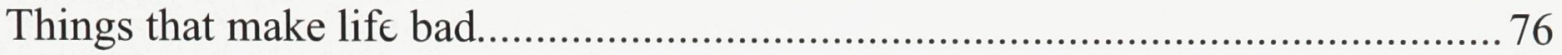

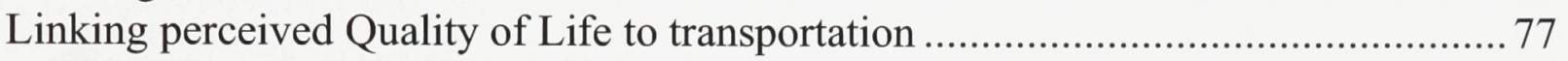

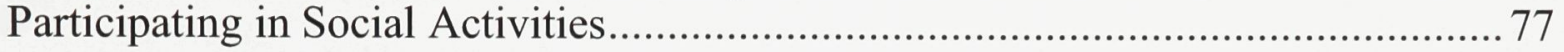

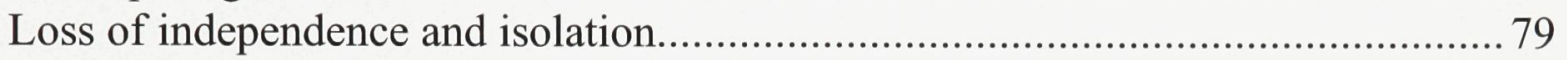

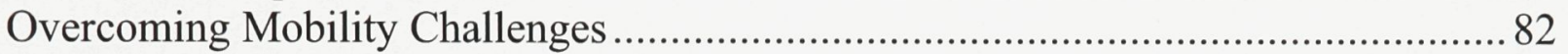

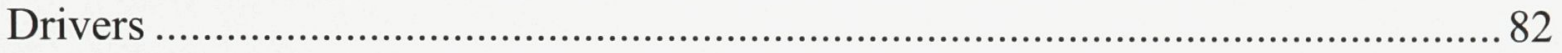

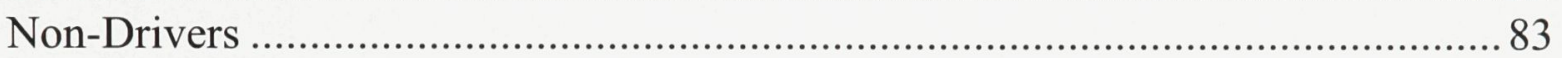

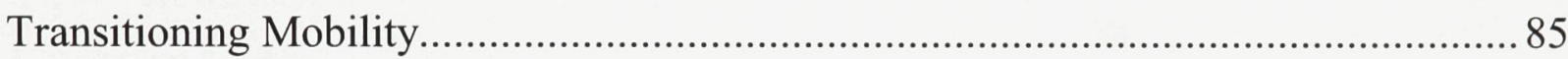

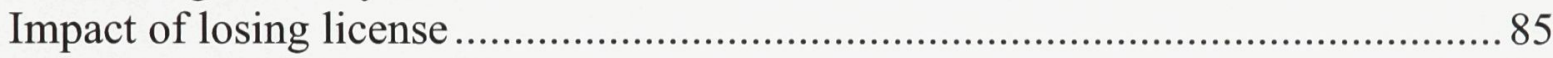

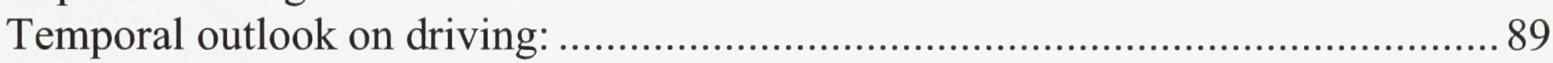

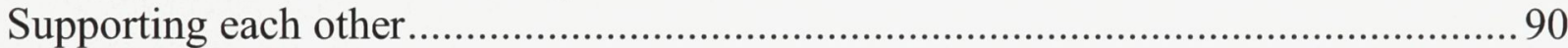

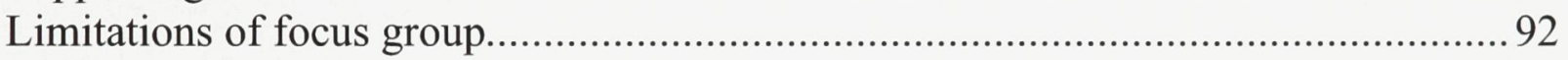

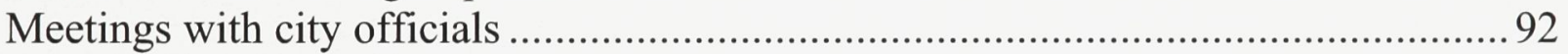

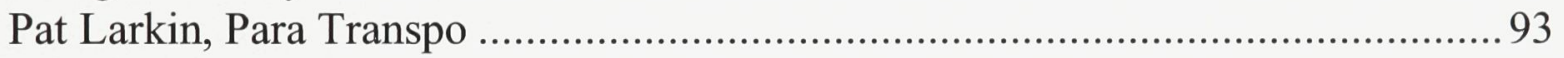

Councillor Alex Cullen (Bay Ward).................................................................. 95

Councillor Clive Doucet (Vice-Chair of Ottawa's Transportation and Transit

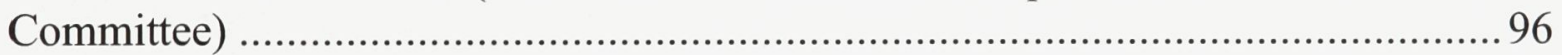

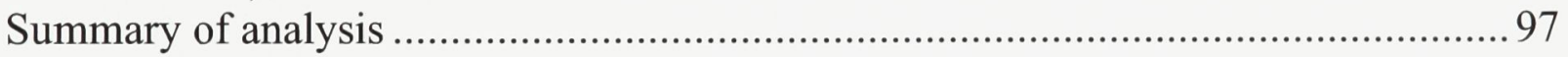

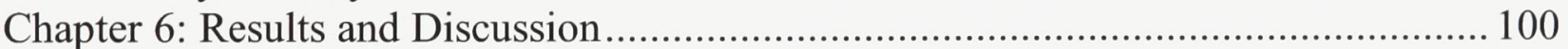

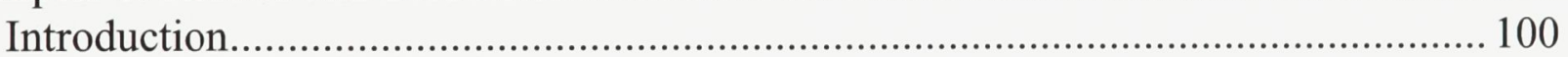

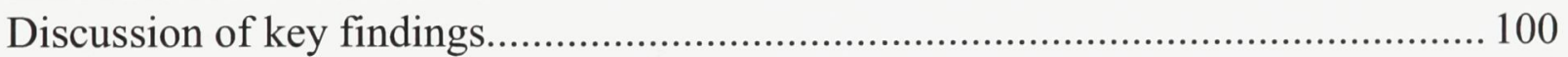

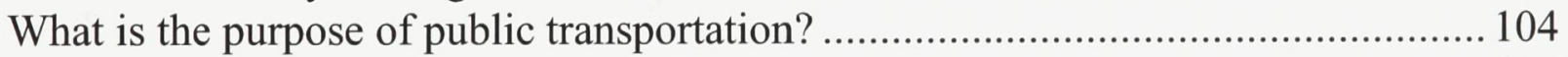

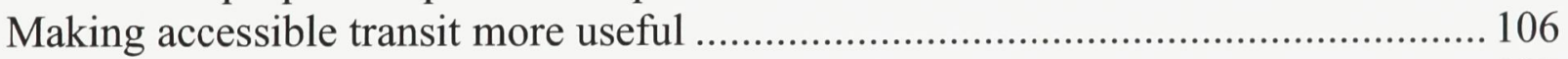

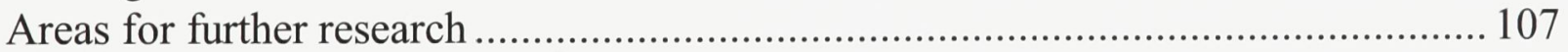

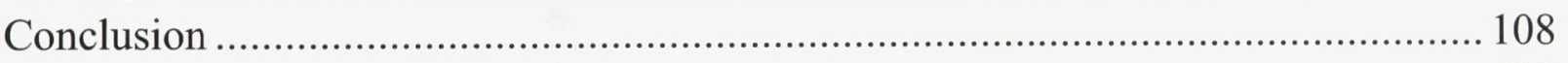

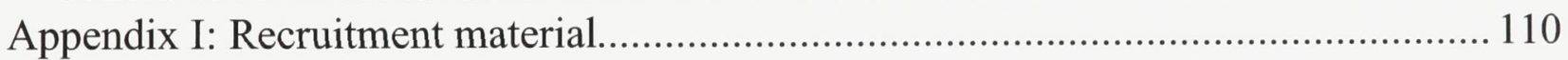

Appendix II: Letter of Information and Consent ....................................................... 111

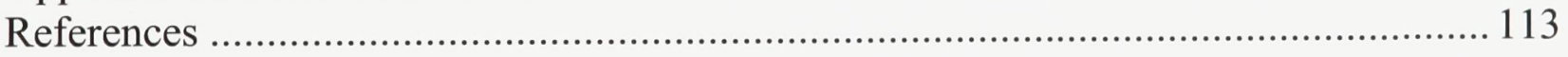




\section{LIST OF TABLES}

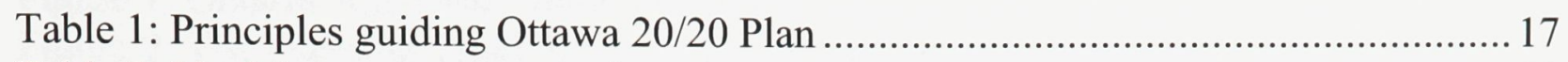

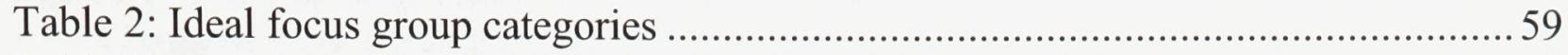

Table 3: Focus group breakdown: locations, participants and dates.............................6 62

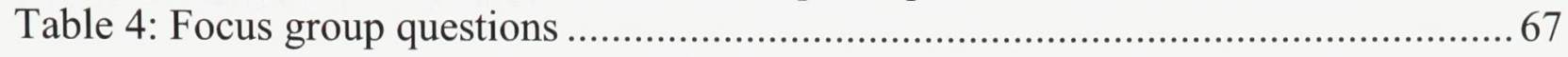




\section{LIST OF FIGURES}

Figure 1: Ontario Age Distribution projection ...................................................... 4

Figure 2: The Planning Triad: housing, health and social services, and transportation

(Derived from Rosenberg and Everitt, 2001) ................................................... 12

Figure 3: Summary of Quality of Life Findings ......................................................... 75 


\section{LIST OF MAPS}

Map 1: City of Ottawa Age Distribution by Neighbourhood ....................................... 33

Map 2: Map of Study Area divided by Census Sub Divisions (derived from Census

Canada, 2001) 58 


\section{Chapter 1: Introduction}

Let me begin by telling you a story about two women. The first lived in Sandy Hill, a neighbourhood in the centre of Ottawa, in the house where she and her late husband raised their family and grew old together. She never had a drivers license, and even after her husband was hospitalized with Alzheimer's, she lived on her own for the next ten years walking and taking the bus every day to visit him, doing her shopping, going to church and visiting friends. The other woman lived across the Ottawa River in Hull with her husband. When all their children were grown, they moved to a farm - her husband's childhood home in the next town over from where she grew up - in a small rural community an hour outside the city. With her husband no longer licensed, she drove fifteen minutes to the nearest grocery store, thirty minutes to the shopping mall and all the way to Ottawa to see a variety of medical specialists in the city. These two women, Grandma Mullen and Grandma Hearty were the inspiration for this research on seniors and transportation, making me question: what would one do without the bus, and what would the other do without her car?

Seniors, particularly the oldest ones, are lumped into the category of captive transit riders. They are the fastest growing age cohort in the Canadian population, and are expected to double in number by 2026 and triple by 2051. Looking at the literature, there are distinct statements made about the lifestyle of this age group. One is that seniors will drive for as long as they possibly can, often well into their 80s and beyond (Alsnih and Hensher, 2003: 904). The second assumption is that the oldest seniors, those over seventy-five years old, are among the most vulnerable and represent a large portion of 
captive transit riders, and that the growth in the number of seniors due to aging baby boomers will increase their demand for public transit (Black, 2001: 6). What do these assumptions mean about seniors' future requirements of public transit? Do seniors need public transit and how does it impact their daily lives? I considered the situation of my grandmother - although she was an avid bus user, she also relied on my parents to help her run errands and drive her places. When she was no longer able to live alone, my mother would drive her to medical appointments, or she would take Para Transpo, or a volunteer from the nursing home where she lived would take her out. She was never a licensed driver, but certainly wasn't captive to public transit as her only means of transportation.

I began to question to what extent seniors are in fact 'captive' to public transit. When talking about commuters and the automobile, we think of alternative modes of transport - do captive transit riders have alternatives to the bus? Are they really 'captive' to public transit in the sense that they have no alternative ways of getting around, or are they simply non-drivers? What other services are available to seniors in this category, and are there community-based services to provide alternative transportation to senior non-drivers in Ottawa?

There exists a contradiction within the literature about aging and mobility. Much of the policy/government and disability literature claims that transportation systems need be accessible to everyone, regardless of their age, physical ability or limited income, particularly if seniors are expected to be able to use public transit (Winter and Williams, 2001; Church and Marston, 2003). Conversely, transportation literature about the driving 
trends of seniors says that they will overwhelmingly prefer to drive, that they will remain doing so as long as possible, and that they will be less likely to use public transit in the future (Rosenbloom, 2001; Newbold et.al. 2004). Therefore the question remains how necessary is an affordable, accessible public transit system in the eyes of senior citizens? Will seniors want to and/or be able to use public transit if they can no longer drive? More specifically, do the oldest seniors, seen as the most vulnerable to the challenges of aging, feel that having accessible public transit enhances their quality of life?

Twenty years ago in a document titled 'Canadian Governmental Report on Aging', the Canadian Government issued a strong statement regarding transportation issues of the aging population:

"Meeting the transportation needs of the aging is a matter of vital concern. Like all others in society, they are dependent upon the ability to travel and have access to appropriate transportation if they are to acquire the basic essentials such as food, clothing, and shelter, as well as employment and health care. When older people are deprived of necessary transportation, their full participation in the life of the community is denied. It is essential that in establishing and operating transportation systems and services, the needs of all older people be taken into account, including those of cultural and minority groups." (Health and Welfare Canada, 1982: 74)

Unfortunately since then in all the research about Canada's aging population and resulting social issues, relatively little emphasis has been placed on the personal transportation needs of the elderly. While research abounds about seniors' current and future requirements regarding health care in Canada (Hanlon and Halseth, 2005; Law et.al., 2005; Woodward et.al., 2004), and to a lesser but still significant extent, housing (Hayward and Lazarowich, 1998), the social component of transportation issues has been 
left behind. "While Canadian policy makers have long recognized the importance of an aging population with respect to Canada's health care system and national pension plan (amongst other issues), the travel behaviour of older Canadians has received surprisingly little attention," (Newbold et.al., 2004: 1).

\section{Age Distribution, Ontario}

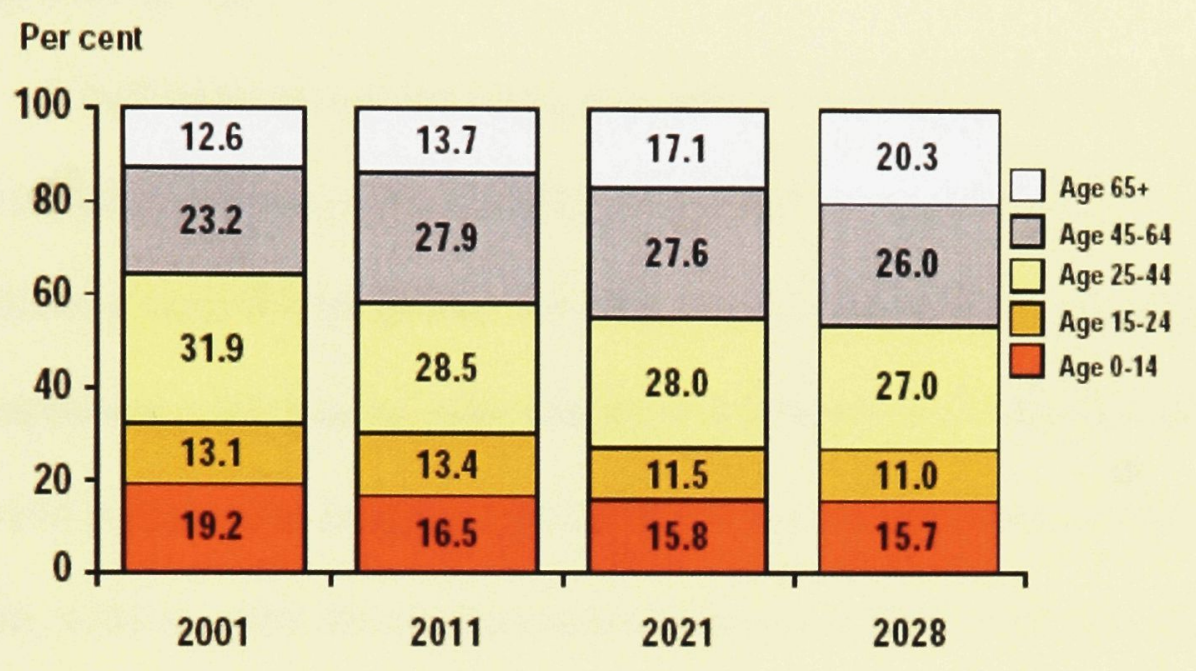

Sources: Statistics Canada, 2001, and Ontario Ministry of Finance projections (Reference Scenario).

Figure 1: Ontario Age Distribution projection

Canada is poised on the brink of significant changes to its age distribution as the baby boom generation approaches retirement in the coming decade. The demographic trends in Ontario suggest that the segment of population over 65 will nearly double between 2001 and 2028 (see Figure 1), and Ottawa will have the second highest rate of growth of seniors in the country (Council on Aging (COA) Ottawa, 2004: 11). Aging is accompanied by significant lifestyles changes, such as retirement, decreased income, worsening health and widowhood (Rosenberg and Everitt, 2001: 146), all of which only begin to distinguish seniors as a unique demographic group within society. Seniors 
overwhelmingly choose to live in urban areas, and this sizeable shift in the age of city dwellers will modify the way people use urban space, the expectations they have of it and the requirements they place upon it. The entrenched automobile-dominated urban development of our cities plays a critical role in how easily seniors can get around and their ability to remain independent when they are no longer able to drive, a key theme presented in Chapter 2.

Challenges facing the aging population in automobile-dominated and increasingly diverse urban Ottawa create a challenging arena for policy makers. “... Older people consist of a very diverse group. This has made it difficult to generalize about the appropriateness of their housing situations and locational contexts and the effectiveness of social policies and programs intended to improve the quality of their lives." (Golant 1986b: 438) As such, the transportation needs of seniors need to be examined in the context of their own lives with respect to the daily problems they face and the priorities they describe. Individuals age differently and have unique economic, racial, ethnic, social and psychological characteristics. Chapter 3 presents how the diversity of seniors, in terms of lifestyle, income, health, mobility and housing has impacts on their need for public transit and the role it plays in enhancing their quality of life.

Research in transport geography is typically approached using quantitative methodology, due in part to its development during the quantitative revolution and also to its multidisciplinary nature, combining elements of engineering, economics and urban planning. However, qualitative methods are used here to examine the needs of seniors on a deeper level beyond that presented by traditional quantitative approaches. Using focus 
groups, this research is able to investigate the causal relationships between seniors' ability to access public transit and their quality of life. Chapter 4 outlines the suitability of such a method to answering the questions posed here, as well as the strengths and weaknesses of the focus group as a technique for eliciting data for this purpose.

Examining the connection between seniors' need for and access to public transit and their perceived quality of life is expected to inform decision makers of the importance of public transit in the daily lives of seniors in Ottawa. As Ottawa begins to implement strategies described in the 'Ottawa 20/20' growth plan (elaborated on in Chapter 2), the tangible impact that changes to public transit service are likely to have on seniors, particularly the oldest ones, may force planners to reconsider what requirements they anticipate seniors to have of public transit in the future, as well as the best methods for addressing them.

And as a final note, while there has been an increasing amount of literature on the transportation and mobility patterns of seniors, much of it comes from studies conducted in the United States, Europe, Australia and New Zealand. Given that Canada shares similar baby boom generation and population age distribution trends with these countries, one would expect to be able to draw some parallels from these studies. Therefore while priority is given to Canadian content, where it is lacking examples will be taken from other countries. 


\section{Chapter 2: Transportation and Planning in the Auto-Dominant City}

\section{Introduction}

The past decades have brought about a heightened awareness of the connection between people and the environment. The concepts of sustainability, 'Smart Growth', and efforts to reduce greenhouse gas emissions are examples of how society is growing in awareness of environmental issues, acting more responsibly and slowly changing its values. The field of transportation has been affected by this shift in values; the need to reduce dependence on the automobile and shift toward alternatives such as public transit is one example. But in cities designed for the automobile, such as the dispersed, midsized cities typical of the Canadian urban landscape (Bunting, Filion and Gertler, 2000), serving transportation needs using public transit can be difficult due to the layout and design of our neighbourhoods. The problem is further confounded by the diversity of people living within these neighbourhoods - young and old, rich and poor, with varying levels of personal mobility.

The problems imposed by the auto-dominant city discussed here are presented in the context of an aging population. An individual without a private vehicle may be at a disadvantage simply due to the physical evolution of our cities. Because land uses are separate and linked primarily by automobile, it becomes increasingly difficult to navigate the city on foot - distances between places are long and access to transportation alternatives such as public transit varies across the city. The link between automobile transportation and land-use is presented in this chapter, followed by a description of the 
transport problem and the difficulties historical auto-dominant planning strategies present for providing future public transit service to seniors aging in the suburbs.

Next, Rosenberg and Everitt's planning triad is used to illustrate the connection between housing, health and social service, and transportation. Arguments for integration versus segregation and equity versus efficiency are outlined as they relate to the approaches city planners take to providing public transit service, followed by reference to the ways the City of Ottawa has adapted these ideas. The plans for future city growth, identified in the 'Ottawa 20/20' report, and the actions taken by OC and Para Transpo are examined to identify a gap between public transit planning in Ottawa and investments in infrastructure. While social planning dictates a fully accessible infrastructure, the network connectivity is overwhelmingly focused on daily commuters. Whether or not this is appropriate for accommodating the trip demands of seniors is examined.

The second half of this chapter deals with how transportation planning decisions are made. The traditional quantitative approaches that transportation geography brings to the field are presented, along with reasons why such methods are unsuitable for this research on seniors and their views of public transit. It concludes with a description of the formal planning process used by municipalities, including their reliance on quantitative modelling and inputs, and identifies how additional consideration of qualitative factors, such as the answers to questions suggested in chapter 1 , can lead to a more complete understanding of how people, in this case seniors, value the service public transit provides. 
The transportation/land-use problem and aging-in-place

Urban transportation is intrinsically linked to land use. Until recently, growth of modern cities has been fuelled by ubiquitous use of the personal automobile. This growth has contributed to the separation of residential, commercial and industrial land uses.

Traditional low-density suburban neighbourhoods are not amenable to walking or transit due to their sprawling layout which, combined with long distances from businesses and commercial land uses, further reinforces the dominance of the automobile. The car becomes the fastest and most convenient method of transportation, and so begins the transport problem.

"Under circumstances in which the public sector is shortchanged, funds for public mass transit decline precisely as the need grows. At the same time, incomes rise in those households who can afford to commute in individual automobiles. Pressures to build roads and manage automobile traffic thus explode, just as the capacity to provide mass transit declines, and the vicious cycle so well known in U.S. cities takes hold" (Goldsmith, 1996:138).

To examine the transport problem requires an equal focus on the land-use problem. To speak of transport while ignoring land use is futile because urban form and land use are at the heart of transportation planning. The automobile broke the transportation/land-use connection by allowing cities to sprawl, and induced severe costs of an endless supply of transport infrastructure catering to exponential demand (Newman and Kenworthy, 1996: 21). 'Urban structure or the pattern of urbanization plays a critical role in determining the volume of traffic, the mode of transport used and passenger travel patterns, and thus passenger kilometres travelled as well as litres of fuel used per passenger kilometre,' (Pargal and Heil, 2000: 666). Perhaps the 'transportation problem' 
is equally a 'land use problem', where the additional driver who enters a highway that has reached its capacity consumes the space allotted to other drivers.

The dominance of the automobile has its perils. While cities require the automobile and roadway infrastructure to function, increasing rates of road use result in increasing demand for roadway improvements and network expansion. Not only is this costly, but once capacity is reached it becomes very difficult to scale down the system (Bunting, Filiorı and Gertler, 2000: 4). Moreover, once patterns of mobility are established, changing them is difficult not only because people are accustomed to the freedom of driving but also because it is difficult to retrofit the system to accommodate different modes of transportation. The design and construction of roads and houses in the suburbs bullies residents into automobile-dominated transport, leaving awkward alternatives for implementing public transit services. There is consensus amongst academics and professionals that 'the present trends in transport are not sustainable, and many conclude that fundamental changes in the technology, design, operation and financing of transport systems are needed' (Greene and Wegener, 1997: 177).

The transport problem is fourfold. According to Bunting, Filion and Gertler's (2000: 8) temporal scale of Canadian city development, our auto-dependent lifestyle began in the post-war 'metropolitan development' stage between 1945 and 1975 and the resulting transportation/land-use patterns have remained a dominant feature of the landscape ever since. The dominance of the automobile is one aspect of the transport problem. A second aspect is surface and global pollution, where incomplete combustion of fossil fuel creates pollutants like carbon monoxide, carbon dioxide, volatile organic 
compounds, nitrogen oxides and sulphur oxides that create acid rain and contribute to air pollution and greenhouse gas emissions (Greene and Wegener, 1997: 178-9). Third, automobile transportation consumes non-renewable resources such as land and oil (Greene and Wegener, 1997: 180), and finally cities cannot be retrofitted to fully accommodate growing demand for private automobile travel and 'the future transition from the automobile to some other, hypothetical mode would be difficult because of the massive financial investment, both public and private, that has been sunk into cars, trucks and different types of roads,' (Bunting, Filion and Gertler, 2000: 4).

Given the relationship between transportation and land use, residential suburbs are a challenging area of the city for public transit to serve. Additionally, research of housing preferences suggests that seniors will overwhelmingly choose to remain in their own home as long as possible, a situation referred to as aging-in-place (this concept is discussed in greater detail in Chapter 3). Given the auto-dominated urban landscape, an individual's ability to remain independent in their own home is greatly influenced by their ability to operate a car. "The future challenges for public transit planners will be how to provide services to an elderly population ... which is aging-in-place in areas least amenable to the operation of public transit services" (Rosenberg and Everitt, 2001: 161). How important seniors themselves view the provision of public transit service within the neighbourhoods they live in is of particular concern since investment into accessible public transit, a strategy employed by the City of Ottawa to deal with the growing aging population, is only useful if seniors will use it. If seniors have negative perceptions of public transit, if they are uninformed or misinformed of its availability, of if it does not 
take them to the places they want to go, then investment in accessible conventional transit may not be an effective means of accommodating the future aging population in the areas they wish to age-in-place.

\section{Conflicting approaches to transportation planning}

From a social planning perspective, transportation falls within a triad of support services available to the public that include housing, health and social services, and transportation, as illustrated in Figure 2. In this light, transportation cannot be discussed independently of housing, or health and social services. Housing decisions are important when assessing seniors' transportation requirements because they alter the availability of health care and social services:

"[t]he keys to remaining in one's home are the ability to access health and social services and transportation. If seniors are to remain in their communities, they need to have access to health and social services either through home care or through the ability to transport themselves by private or public transportation to these vital services," (Rosenberg and Everitt, 2001: 142).

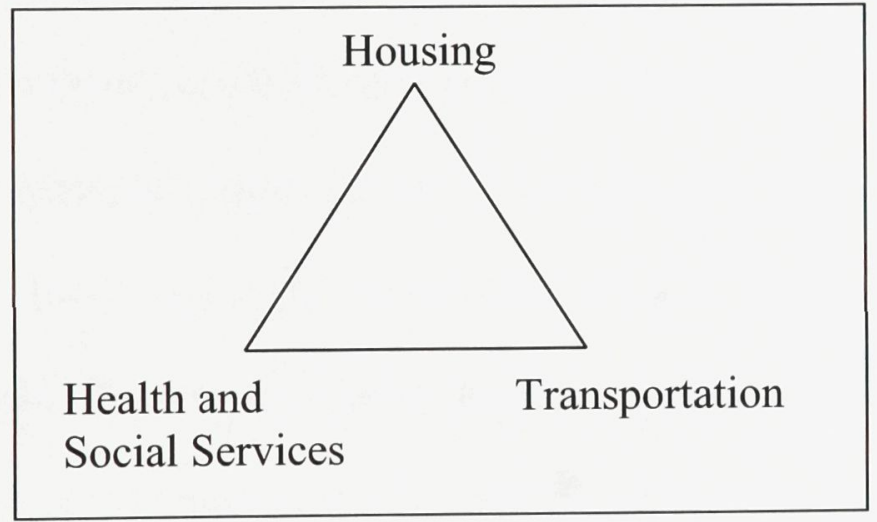

Figure 2: The Planning Triad: housing, health and social services, and transportation (Derived from Rosenberg and Everitt, 2001)

Successful aging-in-place therefore requires support from the community. In order to maintain their independence and stay in their own home, transportation 
alternatives to the automobile must be available once the individual can no longer drive, to allow them to access health and social services.

Bohland and Herbert (1983) provide an example of how housing, health care/social services and transportation are explicitly linked in a study conducted in Swansea, Wales. This study showed that seniors who considered facilities such as shopping, doctors, library, and bus stops more convenient reported better health. Seniors who were able to access social/health care services more easily were able to get around independently, were the most physically mobile, and not surprisingly reported better health. For those seniors who experienced decreased health, physical mobility became a barrier to leaving their home to access social and health services. Overcoming this barrier can be accomplished in several ways: introducing homecare so that seniors do not have to leave their home in order to access medical care, incorporating 'virtual mobility' into the services seniors require on an ongoing basis (such as 'meals on wheels' programs, grocery delivery, pharmacy delivery), or by modifying transportation to ensure that all seniors, regardless of physical limitations, have the ability to get from their home to the social and health care services they need.

Rosenberg and Everitt (2001) present conflicting approaches of integration and segregation in their discussion of planning for an aging population. A key assumption of the integrated approach is that, "full integration of the elderly population within their communities is the best way to ensure maximum life satisfaction of the elderly population over the longest period of time," (120). This manifests itself in fully accessible public transit systems (i.e. retrofitting current infrastructure), permissible 'in- 
law suites' built in areas zoned for single-family dwellings and community care operations, amongst others. Conversely, proponents of the segregated perspective claim that, "the elderly population prefers a built environment created exclusively for them and which specifically caters to their particular needs," (Rosenberg and Everitt, 2001: 121). Examples of this approach include separate transit systems catering to the limited physical abilities of seniors (such as Para Transpo), gated/seniors-only communities, and 'pay as you go' health and social services.

A second theme presented by Rosenberg and Everitt of equal merit to this discussion is the conflict between equity and efficiency. With reference to public transit, they explain:

"Making public transit systems fully accessible to seniors regardless of their physical ability is based on treating everyone equally even if it means the additional costs of retrofitting buses and stations must be carried by society as a whole. In contrast, creating separate transit services tends to be more efficient in cost-benefit terms, but no longer treats everyone equally," (121).

Rosenberg and Everitt (2001: 149) suggest that future housing policy and planning strategies will encourage seniors to remain in their homes as long as possible, encourage a wider variety of housing options (in-law suites, gated communities) and improve and increase home care services. It would follow that in order to maximize seniors' potential to remain independent as long as possible, access to alternative modes of transportation must be addressed (Alsnih and Hensher, 2003: 909). The homes the elderly occupy tend to be located in low-density residential areas inherently dependent on the automobile (Rosenbloom and Morris, 1998). Considering that the former cities of Kanata, Gloucester and Nepean are seeing enormous growth in the number of seniors 
residing in these areas (COAOttawa, 2004: 12), losing access to a private vehicle and/or driving license significantly alters the transportation alternatives available to them. As mentioned, the structure of the suburban built environment is known for being unfriendly to pedestrian traffic, and access to fixed-route public transit varies greatly in terms of walking distance to bus stops, available facilities such as seating and shelter, frequency of service throughout the day/week, directness of routes and vehicle accessibility. Inflexible public transit is often considered a last resort compared to the convenience of driving (Alsnih and Hensher, 2003: 910). In order to help seniors successfully age-in-place, the relationship between seniors' attitudes towards public transit and their needs of the system must be addressed to ensure that individuals do not end up 'stranded' in the suburbs.

\section{Transit Planning in Ottawa}

The current public transit solutions available in the City of Ottawa encompass aspects of both the segregation and integration perspectives on transport and land-use planning. OC Transpo's move towards a more accessible system to accommodate people with disabilities by acquiring only accessible vehicles, retrofitting bus stops and offering training and help to passengers with special needs (such as those who are blind, who require a companion and/or mobility device and so on) encompass aspects of the integrated perspective of public transit. Para Transpo, offered only to passengers referred by a doctor who endorses their short or long-term need for door-to-door transportation, exhibits traits of a segregated system. It operates independently of fixed route OC Transpo and caters to the specific needs of people with disabilities. Financially speaking, 
these systems make sense: "Canadian experience suggests that the specialized transport system is more cost effective when compared to aging public transport networks that require updating, to accommodate the aging populations' needs," (Alsnih and Hensher, 2003: 910).

\section{Planning Ottawa's future public transit}

'Ottawa 20/20' (City of Ottawa: 2003a) is the city's growth management strategy, developed out of concern for the future growth of the new City of Ottawa following the amalgamation of 11 rural and urban municipalities into a single regional municipality. Following public consultation, the 20/20 plan follows seven guiding principles, listed in Table 1. These principles incorporate a wide range of ideals. For example, 'a caring and inclusive city' incorporates the need for all people in Ottawa to feel safe, have access to adequate income, food, clothing, transportation, housing, health services and recreation, ensure that everyone is able to fully participate in the community, that cultural and social diversity is respected and celebrated, that all people have access to services that respond to special and diverse needs and finally that seniors have access to the community services they require (City of Ottawa, 2003a: 41). Similarly, 'a green and environmentally sensitive city' focuses on walking, cycling and transit, implementing policies that favour them over use of the car, and facilitate the use of modes of transportation that are "socially accessible, environmentally healthy and economically feasible" (City of Ottawa 2003a: 41). 'A city of distinct, liveable communities' outlines the desire for communities with a range of housing choices, services and facilities accessible by walking, cycling or transit and the need for a barrier-free environment for 
the disabled with frequent, accessible transit (City of Ottawa, 2003a: 41-42). From the 20/20 plan initiative came the Official Plan (outlining rules for physical development in the city, of which the Transportation Master Plan is one part), the Human Services Plan, the Arts and Heritage Plan, and Environmental and Economic Strategies.

\begin{tabular}{|l|}
\hline A responsible and responsive city \\
\hline A caring and inclusive city \\
\hline A creative city rich in heritage, unique in identity \\
\hline A green and environmentally sensitive city \\
\hline A city of distinct, liveable communities \\
\hline An innovative city where prosperity is shared among all \\
\hline A healthy and active city \\
\hline
\end{tabular}

Table 1: Principles guiding Ottawa 20/20 Plan

The Transportation Master Plan (City of Ottawa, 2003b), although falling within the Official Plan and its focus on the physical dimensions of the city, is informed and supported by the other growth management plans. The Transportation Master Plan:

“identifies a vision... that expresses how Ottawa's transportation system can contribute to overall community objectives, and how it should be managed to ensure accountability to residents and taxpayers. It also identifies four strategic directions that are essential to achieving this vision: focusing on transit, influencing travel demand, making efficient use of resources, and forging a community partnership" (p.i).

The Transportation Master Plan is overwhelmingly concerned with managing traffic flows, reducing vehicle trips and altering the current modal split towards an increase in public transit use, cycling and walking. In its focus on public transit, it is primarily concerned with strategies to coax daily commuter passengers (specifically during the afternoon peak hours) from their cars. In order to increase ridership, the city intends to expand the current transit system, guided by six key elements: essential supporting measures (e.g. land use planning), transit service improvement (e.g.with 
respect to fares, service to rural areas etc.), transit service for customers with disabilities, transit priority initiatives, rapid transit system expansion, and fleet expansion and replacement (City of Ottawa, 2003b: 43). In short, the future transport planning guidelines outline methods to reduce car use in the city (consequently reducing spending on roadway infrastructure and tackling environmental issues) by targeting commuters and encouraging them to use public transit.

Public transit service within Ottawa is adopting an accessibility strategy in order to accommodate a wider range of passengers with disabilities. This strategy, put into action partially in recognition of the City's growing aging population, sees no expansion of Para Transpo service; instead, OC Transpo fixed route service is being retrofitted in order to make the system fully accessible by 2015 . In doing so, the City hopes to shift the anticipated growth in demand generated by the aging population away from costlier Para Transpo and onto fixed route transit, with hopes of better accommodating all passengers involved (personal communication, Pat Larkin, OC Transpo, July 15 2005). This approach is based on 'accessible transit' as the removal of physical barriers that would otherwise prevent individuals from using fixed route transit (e.g. exclusive use of low floor kneeling buses, increased number of bus shelters and benches).

The removal of physical barriers is one hurdle to achieving a truly accessible transit system. A second and equally important component is the connectivity of the route network, or more simply, the system's ability to get you where you want to go. There exists a gap between the approach outlined in Ottawa's Transportation Master Plan and the strategies employed by OC and Para Transpo. The City explicitly outlines in the 
Plan and illustrates in its investments in the removal of physical barriers to public transit, that it is aiming to accommodate individuals with disabilities. However, its focus on reducing automobile trips by enticing drivers onto public transit results in a route network focused heavily on commuter trips. The Transportation Master Plan is by no means flawed in its focus on commuters, but in the context of this research, it may not anticipate the future needs of an aging population.

As it stands, the City is moving toward a fully accessible hub and spoke network. Commuter trips in Ottawa are focused on moving people from the suburbs (e.g. Kanata, Nepean, Orleans) to the downtown core using 'peak' local services connecting to trunk routes along the Transitway. These feeder services are time sensitive, operating only in the morning and afternoon rush hours, joining frequent and rapid bus routes servicing downtown Ottawa. The travel patterns of seniors are unlikely to mimic those that the system is primarily concerned with serving. Seniors' leisure activities and shopping trips, for example, are more likely to be within their own region of the city. These trips require local services operating in a more fully connected network configuration. Asking individuals to describe how important local bus service is to them and how it affects their daily lives is one way to begin evaluating whether or not the city needs to reconsider how the route network of a fully accessible OC Transpo system is to be configured.

\section{Researching Transport Geography}

Up to this point, this chapter has addressed questions of 'why' it is important to look at seniors' views about the utility of public transit in their lives. The following section is concerned with 'how' research in transportation geography can accomplish 
this. Beginning with the evolution of transportation geography as a field, it ends by discussing the weaknesses of traditional quantitative approaches in answering the questions posed here about seniors' public transit needs.

The origins of transport geography are European, dominated prior to 1950 by French geographers researching 'circulation' (Hurst, 1974: 4), and focused on different modes of transport and the commodities associated with each. As Americans began to study the field, geographers like Ullman and Jefferson concerned themselves with classification, descriptive mapping and mapping flows (Hurst, 1974: 6). Despite their differences, Hurst notes that early European and American transport geographers lacked an appreciation of the significance of both cultural and societal insights.

The onset of computer technology and linear programming shifted transportation geography towards quantitative methods, spatial analysis, regional science and the “newly developing interdisciplinary location analysis field" (Hurst, 1974: 5). The introduction of Christaller's work on central place theory and the adoption of Gravity models fused the fields of transportation and economics. Perhaps the greatest influence on the field was the quantitative revolution of the 1970s, where statistical analysis became a widespread approach for predicting transport patterns and behaviour. During this time, however, there were some transport geographers who began to question the lack of sociological and cultural insights captured by the scientific method (e.g. Buttimer 1969, Parson 1969). More recently, transportation research has increasingly emphasized human behaviour, decision-making processes and experience in addition to statistical analysis (e.g. Jensen, 1999; Gaber and Gaber, 1999; Kaufmann, 2002). 
The history of transportation geography describes the ongoing struggle between quantitative models, statistical explanation of movements and flows, and the human component of travel behaviour. This conflict has its origins in the multidisciplinary nature of transportation as a discipline, combining engineering, economics, urban planning and geography, as well as the multi-dimensional nature of transport problems as described earlier in this chapter. For example, civil engineering's role in transportation falls within the design, construction and safety of transport infrastructure, and economics informs the decision-making process using models to quantify the costs and benefits financial, social or otherwise - of transportation policy choices. Transportation Geography may combine economic evaluations of mobility patterns in the city with social decision making processes and human behaviour. Hurst (1974) summarizes how important it is to combine all of these perspectives when considering transport networks: "Neither the stock piling of facts about transport networks nor excessive attention to optimal solutions or abstract spatial analyses will help us to explain or understand transportation within a societal setting"(4).

Understanding transportation within a societal setting is key to the way this project approaches transportation research. This thesis aims to explore how accessible public transit influences the day to day mobility patterns and quality of life of seniors, capture how meaningful or insignificant accessible public transit is and evaluate the relative value individuals place on public transit service in the context of their lives. In doing so, it provides insights into how useful and worthwhile accessible public transit is to an aging population, how effective the City of Ottawa's public transit strategies are in 
the eyes of its future target audience and indicates if it is an area worthy of more or less financial investment. Transportation traditionally approaches problems in a quantitative way, but these methods are unsuitable for this particular investigation.

Quantitative methodology implies data can be collected impartially, compiled and manipulated statistically to identify variables (dependent, independent), trends and patterns, and then predict future patterns within calculated levels of precision (closeness of multiple predictions to each other), accuracy (magnitude of error between prediction and reality) and validity (how well the phenomena being measured represents what is being explained by the result). For example, a quantitative survey could ask participants to rank reasons why they do not take the bus (such as 'too expensive' 'far walk' 'long wait time' and so on), or use a Likert scale to measure attitudes, preferences and subjective reasons for choosing different transportation methods. The results can be tabulated to describe the attitudes, preferences and subjective reasons in terms of trends but would be unable to explain why they were so. In contrast, qualitative methods allow the reasons behind attitudes, motivations, behaviour and decisions with respect to transportation to be explored more deeply. Despite the tendency for transport research to consider problems from a quantitative perspective, qualitative methods are better suited to the questions raised here, as will be discussed in detail in Chapter 4 .

\section{Informing the transportation planning process}

Given that this research aims to better inform decision makers about seniors' views of the significance of public transit in their lives, standard methods of informing the transport planning process are presented here. The transport planning process used 
in municipal decision-making is similar to research in transport geography in that quantitative data and models are preferred as a means of predicting future travel behaviour and evaluating policy decisions. In this section, an outline of the transportation planning process is presented, followed by a discussion of the weaknesses inherent within it.

The process begins with the identification of the goals and objectives of the transportation plan. Pas (1986: 54) refers to this as the pre-analysis phase involving four components: problem/issue identification, formulation of goals, formulation of objectives, and operationalization of smaller, concrete objectives. To achieve these objectives, data are collected. Black (2003: 221) identifies four data inventories needed for the planning process: economic activity and population, land use, travel characteristics, transportation facilities. Pas (1986: 54) suggests that sample data for use in planning public transit might include information about service areas and route structures, and a survey of sociodemographic transport patterns at the household level. Such a survey, collected through home interviews, telephone or mail, would focus on origin-destination characteristics of trips taken, the number of trips taken, time, mode, purpose, and so on. A final component of pre-analysis is to identify desired standards attached to the planned objectives (Black, 2003: 221), such as to have $90 \%$ of bus routes operating with low-floor accessible vehicles.

The second phase, technical analysis, is highly dependent on modelling. "The purpose of this particular phase is to analyze the data collected during the inventory, determine functional relationships, and then model them" (Black, 2003: 222). Inventory 
data are replicated and then used to predict future patterns. There are a variety of ways to dissect and analyze the flow of traffic across the network; however the types of models used to do this generally fall into one of two categories: aggregate and disaggregate models. Aggregate models analyze travel patterns between zones whereas "disaggregate models focus on individuals or households as the basic unit of analysis," (Taaffe et.al., 1996: 342). Aggregate models are concerned with the number of trips that begin and end in a particular traffic zone, what factors in each zone account for the volume of flow between them, and what explains the size of flows based on attractiveness and distance between zones (Hanson, 1986: 18). The use of disaggregate models grew out of social criticism of traditional planning in the USA in the late 1960s. At that time problems emerged having to do with the destruction of low-cost housing and inner-city neighbourhoods to allow for highway expansion, less affordable and less available public transit services and increasing mobility difficulties for the elderly and disabled, as well as environmental concerns over increasing growth of automobile ownership and use (Taaffe et.al., 1996: 340). In contrast to aggregate models, they consider individual sociodemographic and behavioural factors when analyzing transportation patterns. Disaggregate models, also referred to as behavioural models, are used to uncover the reasoning behind travel decisions, what affects preferences for different modes and what trade-offs individuals are willing to make in their travel decisions (Taaffe et.al., 1996: 342). Generally speaking, aggregate models are more appropriate for long-term largescale planning whereas behavioural models are better suited to smaller scale project planning (Taaffe et.al., 1996: 360). 
Finally, the post-analysis phase is a fourfold process. First, the alternatives are evaluated based on output from the technical analysis. The evaluation can be performed in many ways, but the most common are as a cost/benefit analysis, as a goal achievement analysis or as a cost effectiveness evaluation (Pas,1986: 65). In each case, inputs and outputs are quantified in terms of dollars or weighted on a scale of relative importance and judged based on the objectives set out in the pre-analysis phase. Based on the outcome of this evaluation, the decision is made and implemented, followed by a commitment to monitor the system and re-evaluate if necessary.

The urban transportation planning process presented here is heavily dependent on quantitative inputs and outputs. The analysis of traffic patterns (automobile, transit, cycling, walking) is dominated by empirical modelling that identifies current levels of use and predicts future supply and demand of varying modes of transportation. Although disaggregate models consider the decision making process of an individual, they assign utility values to different trip attributes, and therefore the trip generation is based on highest total utility. The process is critiqued for being overly supply-oriented and for being susceptible to the cumulative nature of errors (since errors are possible at each stage of the modelling process) (Black, 2003: 225). Most important to this research is that the behavioural models described are not used as often as aggregate ones: "the planning process is based on aggregate relationships and really has very little to say about travel behaviour" (Black, 2003: 225) and "current transport planning makes it very difficult to consider issues of major importance today, such as sustainability, 
environmental justice, and so forth," (Black, 2003: 226), as well as the needs of an aging population.

A final assumption made by transit models is that people behave rationally, understood in economic terms as meaning their behaviour is dominated by profit maximization. Planners have 'accepted a distinctively capitalist definition of rationality, connected to the accumulation of capital and the social control of labour power,'(Harvey, 1984: 3). Ey focusing on society as a whole, models assume a homogenous, capitalist audience and may ignore differences in social welfare, environmental beliefs, and political viewpoints. These assumptions imply that individuals are financially motivated, overlooking the impacts of physical disability, age, gender, safety and fear in transportation choices. The need for greater consideration of diversity and changing social values in transit modelling and transit planning is therefore valuable to the successful operation and use of public transit in cities. It is the consequences of these assumptions that are accounted for in this research, following the advice of Harvey (1984: 2): that "the form and content of geographical knowledge cannot be understood independently of the social basis for the production and use of that knowledge."

\section{Conclusion}

The past fifty years of land use planning will have a profound effect on the ability of future city planners to provide seniors with transportation alternatives to the automobile. The separation of residential and commercial land uses results in increased difficulty in providing equitable and efficient public transit services that cater to all individuals rather than focusing on commuters. Despite traditional quantitative 
approaches, the decision making process used by city officials require reconsideration of what data should be used to inform the process. It is my contention that there are weaknesses to the methods currently in place and that additional insight may be gained through a deeper understanding of the attitudes that individuals, in this case seniors, have towards public transit now and in the future. 


\section{Chapter 3: Aging and Quality of Life}

\section{Introduction}

As Chapter 1 presented, there are two common assumptions made about the mobility of seniors - first is that they will drive as long as they possibly can, after which point, or unless they never drove, they become captive public transit riders and increase demand on public transit. Seniors are no doubt a group with certain difficulties compared to the rest of the population, but they are quite diverse in terms of ability, health, activity and so on. This chapter highlights the diversity of seniors, the variety of challenges they face and the range of ways they adapt to changes and cope with difficulties. In doing so, this chapter demonstrates the critical role transportation plays in several dimensions of seniors' lives.

To begin, demographic trends in Canada and Ottawa as predicted by the 2001 Census are presented, highlighting the proportional growth of seniors in both populations. Next, the traits of Ottawa seniors describe what makes aging in Ottawa unique from other Canadian cities. Common challenges facing seniors, including health and community care, housing, transportation and driving cessation, income, isolation and class, gender and race/ethnicity are identified and described with particular reference to how each relates to an individual's ability to access personal transportation. This chapter concludes with a discussion of quality of life - both how it is defined and how it is measured for use in determining how seniors see access to public transit as impacting their perceived quality of life. 


\section{Aging in Canada}

Strictly from cohort analysis, the age structure of the Canadian population is shifting as the proportion of elderly people increases and seniors grow even older than before. According to medium growth projections, the median age of the Canadian population in 2000 of 36.8 will increase to 43.6 by 2026 and to 46.2 by 2051 as the baby boomers age (Statistics Canada, 2001: 65). Statistics Canada estimates that the oldestold, those over 80 years, will be the fastest growing age group of elderly Canadians over the next twenty five years and beyond. Based on 2001 Census projections, this group will double in size by 2026 to 1.9 million and increase nearly fourfold to 3.3 million by 2051 (Statistics Canada, 2001: 66).

The overall proportion of seniors relative to the total Canadian population is also expected to grow. The proportion of persons over 65 will increase from 13\% in 2000 to $21 \%$ in 2026 and $27 \%$ by 2051 (Statistics Canada, 2001: 66). Furthermore, the aging index, a measure indicating the relative 'youthfulness' of the population, shows that in 2000 there were 65.8 persons over 65 years old for every 100 persons under 15 ; by 2026 estimates of the aging index range between 125.5 and 159.1, and by 2051 persons over 65 are expected to be double the number of persons under 15 based on the most conservative estimates (Statistics Canada, 2001: 65).

It is important to understand the assumptions made by Statistics Canada in producing these figures. The predictions are based on low, medium and high growth scenarios as determined by fertility and mortality rates and immigration and emigration flows. The fluctuations in fertility rates account for the majority of trends, and 
immigration levels are assumed to be constant from 2006 and beyond (Statistics

Canada, 2001: 31). Therefore although population projections account for the contribution immigration makes to the net growth in population, the rates are based on constant levels of immigration from 2006 up to the end of the projection scenario (as far as 2051).

Gender is an important issue when discussing aging because women have a longer life expectancy than men. Women, many of whom are widows, far outnumber men within the $75+$ age group. The projected sex-ratio of this age group is expected to change as the population of seniors grows over the next three decades. Although women will still outlive and outnumber men in this age category, a greater number of men will enjoy increased life expectancy brought on by medical science and healthier lifestyles. As a result, the sex-ratio will shift in favour of males. In 2000 there were 60 males for every 100 females, and by 2026 and 2051 this is expected to rise to between 70 and 77 (Statistics Canada, 2001: 70).

Ethnic diversity is another issue to consider when looking at Canada's aging population. According to the National Advisory Council on Aging (1999: 13), immigrants account for $26 \%$ of seniors in Canada with the great majority of them arriving prior to 1961. "The amount of time that has passed since immigration and age at landing affect the poverty rate, knowledge of institutions and adjustments to Canadian society... after 10 to 20 years, immigrants reach a level of prosperity comparable to the general population," (NACA, 1999: 13). Most seniors have lived their adult lives in Canada, worked and raised a family here, adjusted to the culture and social services available and 
speak either English or French. In fact, only $4.5 \%$ of all seniors across Canada do not speak either official language. Nearly all immigrants who arrive in Canada as a senior are classified under 'family reunification', and in 1997 accounted for only 3\% of total immigration to Canada (NACA, 1999: 13).

\section{Aging in Ottawa}

Ottawa's population is not only aging but growing overall. Combined with the distinct traits of its seniors, Ottawa is a unique place to grow old. Ottawa's population is expected to grow by $60 \%$ over the next thirty years to a total population of 1.25 million (COAOttawa, 2004: 20). The number of people over sixty-five is expected to triple, and those over eighty-five will increase 3.5 times. By 2031, 22\% of Ottawa's total population is expected to be over 65 years old. While Ottawa saw an $18 \%$ increase in total population between 1996 and 2001, 40\% of it consisted of people over 65 years old (COAOttawa, 2004: 5). Therefore both new city growth and the aging of current residents will contribute to the increasing proportion of seniors in Ottawa.

The amalgamation of the new City of Ottawa in 2001 moved it from $2^{\text {nd }}$ place in terms of the oldest population of all major Canadian cities to well below the provincial and national averages. However, Ottawa now has the $2^{\text {nd }}$ highest rate of growth of seniors in Canada, after Calgary, a result largely attributed to relocation of seniors to Ottawa (COAOttawa, 2004: 11). Currently the old City of Ottawa has the greatest proportion of the population over sixty-five, but this rank is expected to change as former municipalities, particularly Nepean, Kanata and Gloucester, continue growing (COAOttawa, 2004: 12). 
Ottawa's seniors are healthier, live longer, are better educated and have higher average incomes than is true for seniors overall at the provincial and national levels (COAOttawa, 2004: 6). Rockliffe Park, Sandy Hill and the Glebe are noted as communities where the most well-off seniors live. Given Ottawa's bilingual character, French is the first language of $19 \%$ of Ottawa seniors, and $21 \%$ say neither French nor English is their mother tongue (COAOttawa, 2004: 5). Of the French speaking population, $71 \%$ of Vanier and $46 \%$ of North East Ottawa/Sandy Hill seniors speak French as their primary language. The number of seniors whose mother tongue is a language other than French or English increased between 1996 and 2001, with the most popular languages being Italian, German and Chinese (COAOttawa, 2004: 23). These seniors mostly live in the former Nepean, Ottawa South and Central Ottawa neighbourhoods.

Where seniors choose to live as they grow older has profound implications for the transportation and social service infrastructure that the City needs to provide. In Ottawa, seniors overwhelmingly choose to age in place. "Nearly $80 \%$ of those aged sixty five and older in 2001 were enumerated at the same address in the 1996 census, $13 \%$ had moved within the city, $6 \%$ had come to Ottawa from another Canadian community and less than $2 \%$ arrived from outside the country during that 5 year period," (COAOttawa, 2004: 26). The current distribution of Ottawa's oldest seniors across the city is illustrated in Map 1 with Copeland and Pinecrest/Queensway neighbourhoods exhibiting the highest concentrations of seniors over seventy five. This distribution will change over the next thirty years, and although more centrally located condominium buildings in central 


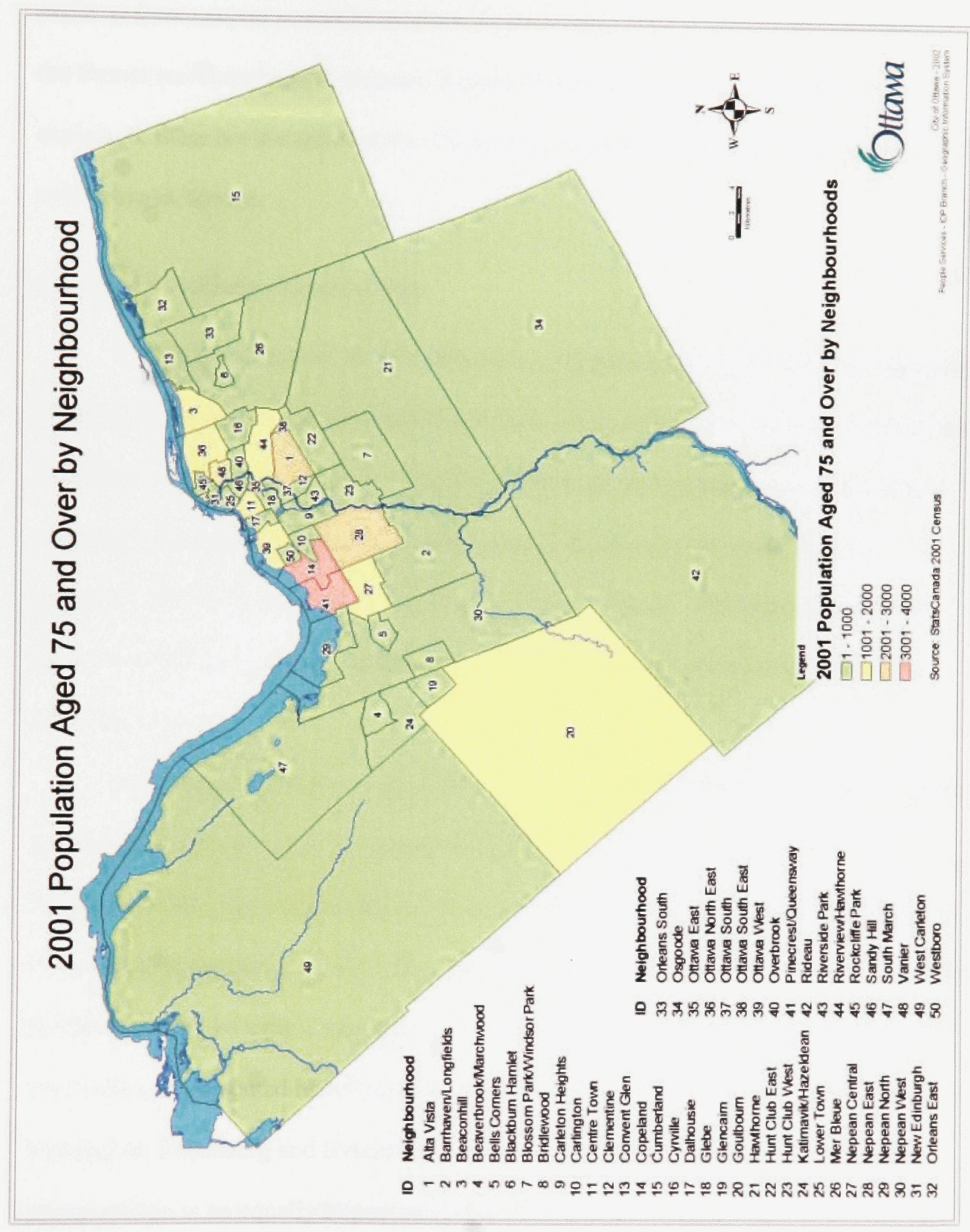

Map 1: City of Ottawa Age Distribution by Neighbourhood 
Ottawa will likely remain a popular relocation choice for some seniors who desire easier and convenient access to services, an increasing number of seniors will reside in the former municipalities of Nepean, Kanata, Gloucester, Orleans. And as Chapter 2 explained, these are the areas of the city posing the greatest challenge to the provision of public transit service.

\section{Common Challenges Seniors Face}

The expected growth in Canada's aging population has widespread consequences. There are economic and policy issues to be addressed, including health care benefits and allocation, appropriate retirement age (if any), pension and retirement funding, policy changes to encourage young person immigration, increased community support programs, affordable housing alternatives and transportation. The following section presents a number of social, medical and economic obstacles commonly faced by Canadian seniors.

Health and community care, housing, transportation and driving cessation, income and isolation are key topics presented but are by no means an exhaustive list. The literature contains an overwhelming amount of information regarding health care issues of the aging population, and to a lesser but significant extent, housing. Despite the higher profile of these two topics, they are not independent of other topics, and in fact most of the challenges presented have some degree of overlap and commonality. Furthermore, building on Rosenberg and Everitt's planning triad introduced in chapter 2, access to transportation is an equally important component of each obstacle. As Cvitkovich and Wister (2001: 810) explain, "effective transportation systems are crucial for minimizing 
social isolation, maintaining connections with the community, increasing access to health promotion and social programs, and improving access to medical services for the elderly". For example, without adequate income, one may not be able to access transportation (private or public) and without access to transportation one may not be able to take advantage of community programs or access regular medical care. Together these obstacles serve to highlight the complicated and interwoven issues plaguing seniors today.

The interaction of age and other social attributes such as class, race, ethnicity or gender intensifies these challenges and is labeled double, triple or multiple jeopardy (McPherson: 144). Double jeopardy refers to the combination of old age with one aforementioned attribute, for example if a person were old and poor or old and female. It follows then that 'triple jeopardy' involves three such attributes, and 'multiple jeopardy' combines aging with four or more. These labels indicate that some seniors are more vulnerable to the problems associated with aging. McDaniel makes reference to this stratified classification system by suggesting that "lower quality of life is experienced throughout the lives of the disadvantaged, and this situation is exacerbated by the onset of old age" (85).

\section{Health}

'Health' is used here to describe not only physiological well-being, but includes psychological and overall well being as well. Generally speaking, seniors are healthy and functionally well until very advanced ages, and despite one in four seniors exhibiting long-term health problems, the majority of them (in all age categories) report their health 
as good, very good, or excellent (Canada's Aging Population, 2002: 9). Only a small proportion $(6 \%)$ reported their health as poor. The levels of health seniors of the future will experience are expected to be better than those of the past and present, due to decreased rates of morbidity relative to preventable disease, and lifelong preventative measures taken against heart disease, stroke, diabetes and cancer (Taylor, 1998: 12). Taylor continues to state that levels of dementia and cognitive impairments, closely related to issues of driver competence, are not expected to change in the future, offering this health challenge as "the single most important factor influencing the health needs of seniors in the future," (12). The most common health problems as reported by seniors are arthritis, rheumatism, high blood pressure, allergies, back problems, chronic hearth problems, cataracts and diabetes (Canada's Aging Population, 2002: 10).

"People's health depends on many factors other than the absence of illness, disease or disability. Income security, housing conditions, stress, workplace safety, family structure, social contacts, leisure activities, happiness with one's situation, smoking, drinking and risk-taking while driving all affect one's health,” (McDaniel, 1986: 80). Social contact and leisure activities are easily linked to one's ability to access transportation and enables them to get out of the house. Ninety-six percents of seniors see a physician every year (Canada's Aging Population, 2002: 11), further reinforcing the link between transportation and health - transportation is clearly required in order to get to and from medical appointments. 
Housing

As seniors age, they confront new housing needs. The most popular choice is to remain in their own home, often termed aging-in-place. Other options include, but are not limited to, moving to a smaller home/condominium building, moving in with a family member, or moving into a retirement community. Che-Alford and Stevenson (1998) estimate that one-quarter of people move when they become seniors, and the majority of these moves result in smaller homes closer to family, usually within less than $50 \mathrm{~km}$ of their original home. The decision to move can be affected by many factors, including widow(er)hood, increased difficulty maintaining and keeping the home, changing health conditions, changing income, and desire to be closer to family and support groups. In Ottawa, the relocation choices made by individuals who now reside in predominantly senior-occupied condominium buildings along major arterial routes (such as Carling Avenue) are representative of this trend, but are still in the minority of cases.

Given that aging in place is the most common choice of seniors, aging community structure and the increasing number of households with members 65 years and older present several challenges to city planners. Taylor (1998: 13) outlines three: first, to provide non-traditional housing options for blended households (in-law suites, parentchild families, two or more seniors living independently, live-in caregivers, and so on), second, to provide inexpensive and efficient transit services from suburbs to local services and centres, showcasing the growing focus on accessible transportation systems, and third, the development and implementation of official city plans that consider the growing need for community based support programs (i.e. home care, meals on wheels), 
neighbourhood health centres and accessible transit. "As single use post-war suburbs mature, planners are becoming increasingly aware of the lack of enabling physical environments for the elderly in these neighbourhoods," (Hayward and Lazarowich, 1998: 15). Urban, social and transportation plans as well as zoning and bylaws must work together in order to facilitate aging-in-place as a viable option to seniors.

\section{Cessation of driving}

One of the greatest fears seniors have is that their driving license will be taken away, leaving them stranded and without the independence to get around as they would like. Seniors overwhelmingly prefer to drive and will continue to drive as long as they possibly can: "Driving cessation is perceived negatively because so many of the elderly are dependent on the automobile, and losing driving privileges is equated with a reduction in their standard of living," (Alsnih and Hensher, 2003: 907). Newbold et.al (2004) claim that Canadian seniors depend on the automobile as their primary means of personal transportation, and go on to suggest that as the population ages, seniors will become less reliant upon public transportation and increasingly reliant on personal automobiles for independent mobility. Women, particularly those over 80 , cease driving earlier than men. Given the longer life expectancy of women, this leaves a high proportion of the oldest seniors as non-drivers. Other predictions about the future driving habits of seniors expect that they will drive well into old age, and remain licensed drivers later in life than previous generations (Alsnih and Hensher 2003).

Alsnih and Hensher (2003) suggest that public transit can only be a viable alternative to the car if routing and timing are more flexible, accessible, clean, safe and 
reliable. If seniors are not using public transportation, this raises important questions about policy, namely "what other options are available that continue to ensure older Canadians the independence, flexibility, and service that they demand and have grown to expect... and does the provision of public transit need to be re-thought?" (Newbold et.al., 2004: 11). Herein lies an important question that has influenced this research - does access to public transit really make a difference in the daily lives of seniors, is it worth spending money to retrofit vehicles and bus stops to cater to an aging population, and will they use it? Where is the balance between social responsibility for those who depend on public transit as their primary means of getting around and fiscal responsibility to the taxpayers who would never use such facilities? And have seniors really considered what might happen to their independence if they were no longer able to drive?

\section{Fixed Income}

Fixed and/or low income is a reality for many seniors, but in particular for the eldest seniors. Predictions made by Taylor (1998: 12) suggest that the gap between well off and poor seniors will widen in the future, and that CPP, retirement investments etc. will dictate what income seniors have. More specifically, elderly women, many of whom are widows, are vulnerable to low income as they age due to the structure of Canadian pension programs. Women who are presently 75 years and older were born in the $1920 \mathrm{~s}$ or earlier, and as McDaniel (1986: 64) explains, with notable exceptions, these women were primarily responsible for their homes and children in a time when the nuclear suburban family of the 1940s and 1950s dictated that the father financially support his family while the mother was a homemaker. While some of these women may have 
returned to the workforce after their children left home, the jobs they found were often low-income, insecure and seldom had pension benefits. As a result, "more of these women, compared to women in subsequent generations, face retirement as widows with no pensions except for the minimal one provided by the Canada Pension Plan," (McDaniel, 1986: 64).

While this explains the situation of the current cohort of elderly seniors, seniors' income profiles are expected to change over the next twenty years. Women currently in their $50 \mathrm{~s}$ and $60 \mathrm{~s}$, the oldest seniors of the future so to speak, may have worked outside the home more than their predecessors, but still tended to work in jobs with limited pension benefits, to suffer a gender gap in their wages and therefore be subject to falling into a similar trap experienced by today's eldest women (Dulude, 1981). Both McDaniel and Dulude additionally point out that problems of low-income will be confounded in the future as more elderly women are divorced, separated or never married.

\section{Isolation}

Closely related to housing and access to transportation is the problem of isolating environments. "Inadequate transportation constricts the life and lifestyle of the aged, limits their ability to be independent, restricts their contacts and opportunities for active interaction with society, and in so doing, adds to their isolation and alienation from society," (Health and Welfare Canada, 1982: 75). If seniors choose to live alone and age in place, as the majority prefer to do, social interaction can become difficult without the ability to drive to organized meetings and activities, or to see friends and family.

Depending on where a person lives, there may be few alternatives to driving, since transit 
access and frequency varies across the city, taxis can be expensive, asking friends and family to act as chauffeur can be inconvenient and burdensome and walking distances are long and difficult to maneuver, particularly in cold weather.

\section{Quality of Life}

McPherson (1998: 164) outlines a "strong and consistent" relationship between access to transportation and quality of life (QoL). Whereas this chapter so far has highlighted the challenges facing the elderly, the following discussion will focus on how each of them relates more specifically to an individual's personal perception of their QoL. And although seniors have better and longer lives than previous generations, many still live with one or more chronic medical conditions that translate into a functional disability requiring some type of assistance in accomplishing normal daily activities (Abeles, Gift and Ory, 1994: 2). It is from this starting point that the discussion of the relationship between access to public transit and quality of life for seniors begins.

'Quality of life' as a concept is poorly defined or simply lacking in definition throughout the literature, largely because it is a matter of personal or group preference and individuals will value things differently (George and Bearon, 1980: 1). "Quality of life refers to well-being, conceptualized either as the objective conditions of living of an individual, as the person's experience of life, or both," (Steg and Gifford, 2004: 62). Lawton $(1983,1991)$ outlines four dimensions of QoL, which include behavioural competence (functioning in social dimension), subjective evaluation of personal behavioural competence, environmental hindrances and psychological well being/mental 
health. Although health is an integral part of QoL, good health does not necessarily equate with good QoL.

\section{Measuring quality of life}

The term 'quality' in itself implies a subjective evaluation. Because subjective evaluations are difficult to measure, quality of life data are inferred through 'objective' means, such as observable characteristics and knowledge of a person's lifestyle or situation (Stewart and King, 1994: 27). This can be problematic because "inferring subjective quality or well-being from external circumstances does not take fully into account the values, needs, and adaptability of individuals to various life circumstances" (Stewart and King, 1994: 28).

An objective set of conditions or scale upon which to measure quality of life can be problematic considering the wide range of psychological, economic and social factors influencing each individual, and the relative importance of these factors throughout the life course. "Conditions or events of limited importance to younger people may be more critical to an older person's quality of life when trying to maintain integrity, independence, and autonomy... for example, although mobility may be taken for granted by young adults, mobility is often an overriding concern for older adults, particularly those who live alone," (Abeles, Gift and Ory, 1994: 5). A study by Golant (1986a) illustrates this by asking seniors to subjectively evaluate their living situation. Their responses not only provide information about their subjective satisfaction with their housing, but is equally telling about their lifestyle, how happy they are, how physically and mentally competent they are, how accepting they are to overlooking undesirable 
aspects of their environment, what their status is in the community, and how they cope with diversity and adversity. Similarly, in this thesis, by asking participants to evaluate the importance of public transportation in the their own life and by asking them to describe things that add or detract from their quality of life, it becomes possible to gain insight into the overall picture of how public transit affects the quality of life of seniors. This study therefore uses open-ended questions about what makes an individual's life better or worse and what improves or detracts from their personal QoL, asking them to draw on personal experience and opinion of what is important and what is not.

\section{Conclusion}

Aging is a multi-dimensional process. The growing aging population on both national and local scales present serious questions about the way we plan for the future of our cities. Within Ottawa, seniors are likely to age-in-place in suburban areas, making the provision of transit service in these areas important but problematic. The diversity of language and growing number of immigrants increase the difficulty of providing such social services.

Although seniors face common challenges, their ability to adapt and cope varies greatly, reflecting the diversity of seniors as a whole. Health, housing, cessation of driving, fixed income and isolation are on some level all interwoven and intensified by issues of class, race, ethnicity and gender. The discussion of how transportation influences seniors' quality of life must be considered along with these challenges as they aid in understanding the context in which seniors operate. In combination, understanding 
these challenges and evaluations of individuals' perceived quality of life provide insight to the usefulness and importance of public transit access in the context of seniors' lives. 


\section{Chapter 4: Methodology}

\section{Introduction}

The following chapter outlines the methodology used to conduct this study. It begins with a description of the research objectives and an introduction to the use of qualitative data in transportation research. The theoretical grounding for the use of focus groups is introduced, explaining what they are and how they are used both generally in social science and more specifically in the context of this project. Next, the study area in Ottawa and the criteria used to select it are outlined, followed by an explanation of the focus group recruitment process used to encourage seniors in the community to participate. The ideal focus group participants are described, followed by the characteristics of the four actual focus groups conducted during August and September 2004. Finally, the questions used in each focus group and a discussion of the limitations of the focus group methodology and ethical considerations specific to this project are presented.

\section{Research Objectives}

How important is access to public transit in the eyes of the oldest seniors in Ottawa? This research connects the views seniors hold regarding the usefulness of public transit and its impact on their quality of life with plans the City of Ottawa intend to take in the coming years. It aims to highlight how access to different modes of transportation, both private and public, impacts the overall well-being of the elderly, where well-being is defined by characteristics such as self-esteem, level of independence and ability to participate in their community. Using focus groups, the results begin to uncover what 
requirements Ottawa's oldest seniors have of public transit services in order to see how they match current and projected transport plans in the City, if they could be used to better inform future transit policy decisions, and explore the ability of city planers to facilitate improved quality of life for seniors through their decisions.

Evaluating these seniors' requirements of Ottawa's public transit system in the context of their lives involves several steps. First is consideration of access they may or may not have to a private vehicle and the characteristics that influence driving ability, such as declining health and subsequent loss of a driving license, death of a spouse who was the primary driver, or lack of confidence behind the wheel. Next is the issue of transit accessibility, which incorporates the physical ability to get to and wait at a bus stop, ease of boarding the vehicle, understanding the system, confidence using transit to get between origin and destination, and scheduling and frequency of service. These influence whether or not seniors feel they are able to use transit to accomplish their daily activities. A final aspect of seniors' requirements of Ottawa's public transit system is the access they may have to onsite medical services, retirement community programming, grocery delivery services, community support/social programs or other forms of 'virtual' mobility. Considered together, it becomes clear that there is a need to recognize and understand the heterogeneity of seniors' living conditions and circumstances in order to appreciate how important public transit is to them.

This problem is divided into three parts. First, how does the availability of other services (municipal, volunteer, private) impact seniors' need for public transit? Second, how does access to public transit impact perceived quality of life? Finally, what do the 
insights gained with regard to the connection between public transit access and quality of life of seniors mean for future transit planning decisions made in the City of Ottawa?

It is important to note that this is study is not intended to look at methods of encouraging or altering ridership levels of public transit in Ottawa. This study looks at seniors who may be captive transit riders and it recognizes that seniors, like any other group of people, will choose the automobile as their first choice of transportation and will remain drivers as long as possible (Alsnih and Hensher, 2003: 904). It attempts to identify seniors' critical transit requirements in order to raise awareness of the equity issues involved in planning for an aging population in an auto-dominant city and allocating scarce funds to public transit. In so doing this analysis adds a social component to an economic-efficiency based decision-making process as has been discussed in Chapter 2.

\section{Research methods in transport geography}

Chapter 2 discussed the use of quantitative methods in transportation research both its historical use and inherent shortcomings in answering the questions presented here. Qualitative methods are more suitable for addressing seniors' perceived value of public transit and its impact on quality of life issues.

"Qualitative research is concerned with elucidating human environments and human experiences within a variety of conceptual frameworks" (Winchester, 2000: 4). She explains the difference between the questions asked by quantitative and qualitative methods; quantitative methodology draws upon statistical techniques to answer questions about the "relationships between phenomena and places or the differences between them 
(italics in original)" (Winchester, 2000: 4). Qualitative methodology instead poses two questions: first, "what is the shape of societal structures and by what processes are they constructed, maintained, legitimized and resisted?" and second, "What are individuals' experiences of place and events?" (Winchester, 2000: 4-5). The ability of qualitative methodology to explore individual experience and how these experiences are influenced by their position within social structures make it ideally suited to answering the questions posed here. And although quantitative survey methods could have been used to evaluate seniors' opinions, Kitchin and Tate (2000) warn of its shortcomings: "While the questionnaire is useful for asking very specific questions concerning quantifiable information such as age, income and sex or for converting general information into a closed form through rating or ranking, the interview allows a more thorough examination of experiences, feelings or opinions that closed questions could never hope to capture," (213). Qualitative methods are better suited to answering questions pertaining to the relative importance seniors place on public transit service.

A qualitative method - focus groups - is used in a study by Waterton and Wynne (1999) to ascertain community attitudes to the risks of construction of a nuclear waste repository in Cumbria, England. What they found was that the community views collected by quantitative polling and survey techniques did not accurately represent the attitudes of the afflicted community, demonstrating "that focus groups can certainly uncover a far richer sense of community views ... than that ascertained through the poll" (128). This inspired my use of focus groups in the context of transportation research. The majority of transportation data collected by the City of Ottawa (and other 
municipalities) is generated by telephone surveys and results in trip demand, modal

split and other quantitative measures of mobility upon which transportation planning decisions are based. Operating along the same principles of Waterton and Wynne, I opted to use focus groups as an additional way of exploring the causal relationships between seniors and their use of public transit in Ottawa.

Individual interviews with city officials are also used as a means of validating the focus group findings and exploring the opinions and views decisions makers hold regarding transportation planning challenges presented by the growth in seniors. This process informs city officials not only of the results of this project but also reinforces the validity of the findings. "Investigators have long recognized that government officials are more inclined to accept quantitative data that give an overview and are inclined to dismiss as anecdotal qualitative evidence no matter how often they themselves rely on anecdotes for policy justifications," (Hoggart Lees and Davies, 2002: 63). These meetings may help raise awareness of the value qualitative accounts provide to the planning and decision making process.

\section{Focus groups in qualitative research}

A focus group is essentially a group interview, usually consisting of six to ten participants and a moderator, where data are gathered from the conversation, flow and exchange of ideas about the topics discussed. "The hallmark of focus groups is the explicit use of the group interaction to produce data and insights that would be less accessible without the interaction found in a group," [italics in original] (Morgan 1988:

12). Focus group research methodology originated in sociology and is a widespread 
investigative tool for qualitative marketing research (Morgan 1998a: 40). Over the past twenty years, focus group methods have become popular in qualitative social science research as well, but with different purposes and applications.

Morgan (1988: 11) outlines five uses of focus groups: orienting oneself to a new field, generating hypotheses based on informants' insights, evaluating different research sites or study populations, developing interview schedules and questionnaires, and getting participants' interpretations of results from earlier studies. As McCracken (1988:17) states, "qualitative research does not survey the terrain, it mines it", and as such, focus groups are not used to seek broad generalizations of a population. Instead they attempt to uncover deeper meaning. "Through intensive analysis, the researcher should derive a more nuanced understanding of the meanings of social acts, as well as a greater appreciation of interacting and contextualized rationalities that impact on behaviour." (Hoggart et. al., 2002: 202).

Focus groups are not appropriate in all qualitative research, and alternative qualitative social science methods include participant observation and individual interviews (Morgan 1988: 13). In theory, participant observation provides a more naturalistic environment in which people are observed compared to focus groups, and therefore results in more natural or regular exhibited behaviours. However, it is difficult to find and access a situation or environment that is 'true' or 'accurate' or 'natural'. Morgan (1988:17) suggests that focus groups are better suited to research investigating attitudes and cognitions, and participant observation is more suitable for studies of roles and organizations. Individual interviews may have the ability to ask the same questions 
as a focus group, but restrict interaction to dialogue between the researcher and participant, eliminating the possibility of multiple interactions and group discussion (Hoggart et. al., 2002: 214). Barbour and Kitzinger (1999: 5) note that focus groups are well suited for exploring "how points of view are constructed and expressed" whereas interviews are better for "tapping into individual biographies".

"From a social science point of view, focus groups are useful either as a selfcontained means of collecting data or as a supplement to both quantitative and other qualitative methods.” (Morgan, 1988: 10). When used to supplement quantitative work, focus groups are often used as an initial probe into a problem where ideas are introduced and then verified by further research. This is a typical strategy used in marketing focus groups, but is also applicable to the social sciences (Barbour and Kitzinger, 1999: 6; Stewart and Shamdasani, 1990: 15). Focus group data can be used as a platform for developing future survey questions and generating ideas, but can also "challenge how such data are interpreted" (Barbour and Kitzinger, 1999: 7). The aforementioned study by Waterton and Wynne (1999) is an example of this.

Morgan and Krueger (1993: 15) set out guidelines for the appropriate circumstances in which to use focus groups in social science research. They suggest using them in five cases: when there is a power differential between participants and decision makers, when there is a gap between professionals and their target audience, when investigating complex behaviour and motivations, to learn more about the degree of consensus on a topic, and when a friendly research method is needed that is respectful and not condescending to the target audience. It can be argued that the research questions 
posed here about seniors' attitudes towards public transit and its impact on their quality of life could fit into every case described, further justifying the use of focus groups here as an appropriate qualitative method.

Group interaction influences what information is divulged during a focus group because of the dynamic flow of conversation, argument and debate amongst participants. Insights are gained by observing where points of dispute and agreement are, and noting participant behaviour in terms of willingness to back down, defend or change an opinion or point of view.

"Group dynamics can instill confidence by revealing shared understandings, as well as encouraging participants to add to messages other participants provide. This can lead to the divulging of more insightful and sensitive information. Groups enable researchers to explore how views are supported in the face of disagreement, with interaction from participants potentially leading to insight that would not have been secured from one-to-one interviews" (Hoggart et. al., 2002: 215).

Because group dynamics are such a crucial component of the success of a focus group, "purposive sampling" (Hoggart et.al. 2002: 216) predominates. Group composition and compatibility influences an individual's level of comfort and in turn influences how they will participate in the group. A shared social background or interest in a topic can help bring individuals together and make them feel more confident in the discussion (Hoggart et.al. 2002: 215).

The degree of structure used in conducting focus group research is another key consideration for the design of the focus group questions and style of moderating. Focus groups following a rigid structure have greater emphasis on set project objectives, asking specific questions that "produce answers to the research team's questions," (Morgan 
1998b: 46). A less structured focus group is more exploratory and provides insight by listening to what ideas the participants to choose to discuss. "For this approach, both the interview guide and the moderator emphasize learning as much as possible about what is important to the participants," (Morgan 1998b: 47). Hoggart et.al. (2002: 217) explains that the group dynamic is influenced by the actions of the researcher/moderator, and their role changes depending on the degree of structure. Using a rigid structure, the moderator keeps the group discussion directed on the key topics presented by the discussion questions. With less structure the moderator facilitates discussion rather than directs it. Common to either scenario are the skills required to be an effective moderator. This includes "being knowledgeable but not intimidating, encouraging articulation but not interrogating, and actively listening and probing," and being "polite and diplomatic" when dealing with participants dominating discussions and others who are not participating (Hoggart et.al. 2002: 217). It can be difficult to know when the moderator should intervene if the group wanders off topic, since it is "difficult to know if the conversation is leading to an interesting insight or wandering off the point" (Hoggart et.al. 2002: 217).

\section{Ethical considerations of focus groups}

Barbour and Kitzinger (1999: 17) outline three key ethical considerations for focus group research: informed consent, confidentiality and offensive opinions voiced by participants. Anyone participating in a focus group must be provided with a statement of informed consent telling them about the potential risks of participating in the project and their rights as participants (Morgan 1998a: 86). Regarding confidentiality, the 
participants are not guaranteed confidentiality or anonymity in the same way they would be in an individual interview since they are part of a group. Finally, when bringing a group of people together to discuss a topic, there is the possibility that opinions expressed by one person could offend or upset another participant. A closely related ethical problem created by focus groups can arise if the information shared is misleading or incorrect. "In such cases the researcher has a responsibility to provide accurate information," (Barbour and Kitzinger, 1999: 17).

\section{Drawbacks of focus group methodology}

Like any research methodology, focus groups have drawbacks. First, there is little evidence to support the idea that focus groups generate significantly more or better ideas than individual interviews (Morgan 1997: 14). Second, "both participation and expressed views can be affected by anticipations of personal benefit, as well as encouraging participants to express views they think moderators want to hear," (Hoggart et.al. 2002: 216).

Recruitment can be time consuming and difficult, depending on the budget of the project. "If you begin with the mistaken assumption that focus groups are easy to do on a small budget and a tight timeline, you are asking for trouble," (Morgan 1998a: 46). Seeking out individual participants is particularly challenging, and community groups are sought after for easier recruitment en mass. Hoggart et.al. (2002) warn about the problems of relying on gatekeepers in these situations: "you might find that gatekeepers screen participants according to their own agendas, or because of what they see as your agenda... Gatekeepers might also not pass on relevant information to participants, who 
then feel they have participated under false pretenses," (216). Therefore the problems with gatekeepers are twofold: they may either screen participants or facilitate access to participants too enthusiastically without the participant's full knowledge of the situation (Barbour and Kitzinger, 1999: 10).

Analysis of focus group data is done using discussion transcripts. Along with spoken words, non-verbal cues, silences, hesitation, sarcasm, irony and tone additional features that must be considered in order to accurately analyze the ideas resulting from the focus groups. Focus group transcripts require a coding system to record meanings and timings of the responses to ensure results can be replicated, noting that recording these variances "help limit misinterpretation" (Hoggart et.al. 2002: 218).

Why focus groups are used in this research

Focus group methodology is used for exploration, discovery, understanding and interpretation of a topic (Barbour and Kitzinger, 1999: 5, Morgan 1998a: 31) and to capture the attitudes of participants (Morgan 1998a: 52). In this project it is selected over survey methods in order to obtain personal insights and gain a better understanding of how seniors feel about public transit, its usefulness and the importance of it in their lives. Dividing seniors into categories by living conditions (independent versus community residence) and driving status, focus group methodology explores how differences in lifestyle characteristics influence seniors' mobility difficulties and the relative severity of such problems in their lives. This study tries to understand what access to public transit means to individuals; "focus groups are particularly effective in capturing tacit or experiential knowledge, seeing understandings and feelings as socially situated rather 
than independent"(Hoggart et.al. 2002: 214). Using a focus group allows the

researcher to understand the depth of knowledge seniors have about their transportation issues and what they see as pertinent and most valid.

The focus groups used here are modeled after Morgan's (1998b: 52) 'moderately structured' template, where the researcher's focused questions and participant exploration are both needed. The intent of this project is to explore how seniors view public transit, how useful it is and what role it plays in their lives, and ask specific questions about current mobility patterns and use of public/social services, making the moderately structured approach the most suitable. It uses a 'funnel design' (Morgan 1998b: 53) strategy to devise questions and lead discussion. It begins with one to two open-ended questions, leading to three to four central topics followed by several specific questions.

Focus groups are used as the primary means of data collection to complement the economic quantification of worth, cost and benefit typically exercised in the transit planning decision making process. Economic based studies use models to predict patterns and behaviour, and statistical trends can illustrate population characteristics and variations, such as how many seniors own a vehicle or the changes in licensed drivers over the age of 75 over time. What these values and models cannot quantify is the personal situations and adaptations made by individuals. The ability to drive is hampered by many factors, including health, income, confidence, previous experiences, and so on. As these conditions decline, losing a license is a problem seniors face that may not be adequately captured by numbers. Their experiences are unique, adaptations are individual and support networks greatly varied. The methods used to cope with 
significant lifestyle changes contribute greatly to the discussion of the contribution public transit makes to their quality of life. The Canadian Census provides data that can be used to identify mobility trends of Ottawa's seniors, what their income and household characteristics are, their marital status, driving characteristics, education level, modes of transportation and involvement in volunteer work, amongst others. While this information provides a valuable backdrop to the study of the elderly mobility in an urban environment, it lacks a personal connection to the study of mobility and how changes to current operations would impact an individual's day-to-day activities. Focus groups allow these topics to be explored.

\section{Study Area}

Independent elderly over the age of seventy-five in the Carlingwood/West area of Ottawa are the centre of this research. This neighbourhood has the largest population of seniors within this age group in the city, illustrated in Map 2.

\section{Selection Criteria}

Map 2 divides the City of Ottawa by 2001 Census Subdivision and illustrates two distinct pockets of seniors in Ottawa - one in West Ottawa, centered upon the Carling Avenue corridor with the greatest concentration of seniors over 75 years old, followed by pockets throughout the East Ottawa. Similarly, Map 1 (in Chapter 3) breaks down the 2001 Census data by neighbourhood and clearly identifies Pinecrest/Queensway and Copeland as the two areas of Ottawa with the greatest number of seniors over 75 years old. 


\section{Distribution of Elderly Population (75+) in Ottawa}

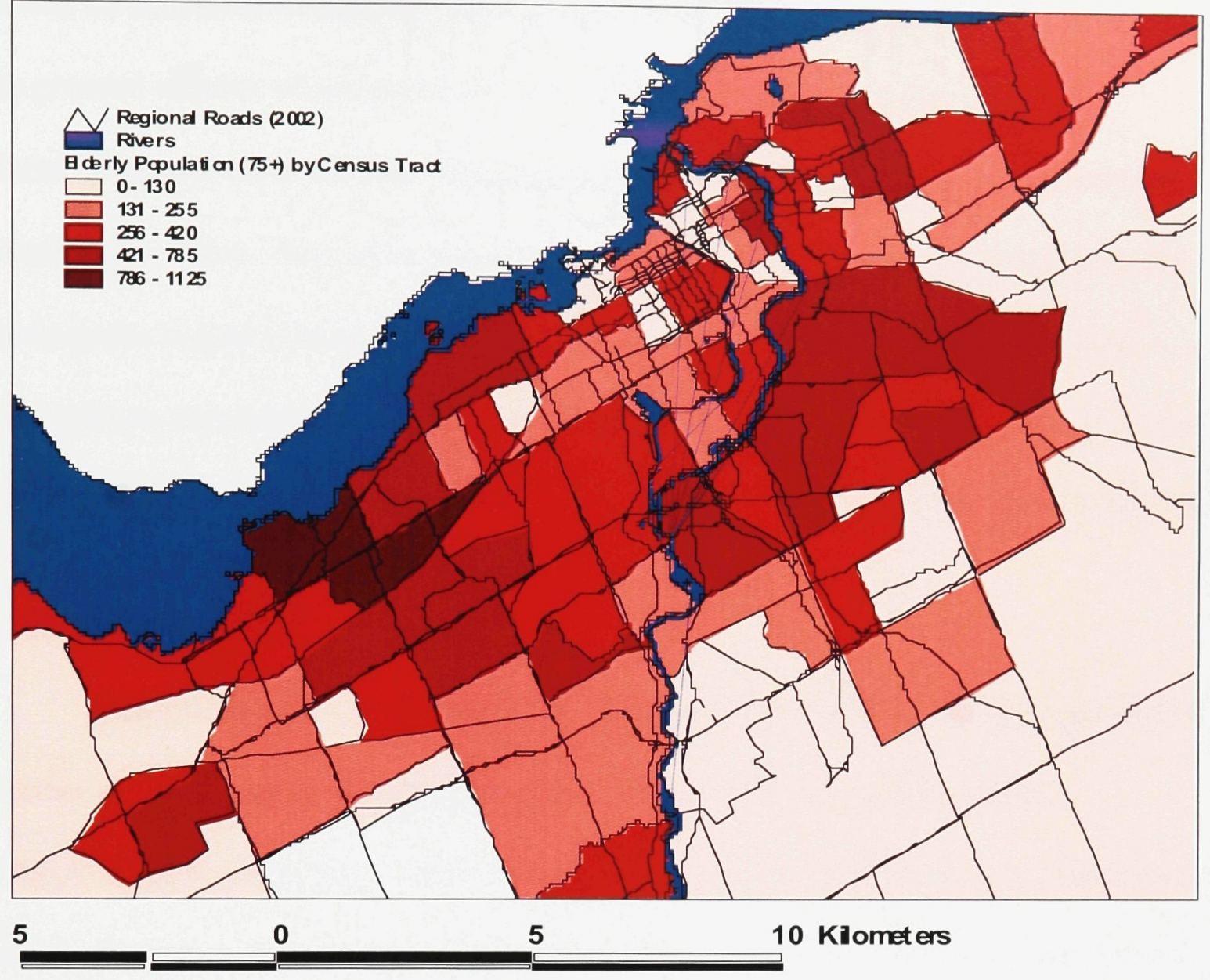

Map 2: Map of Study Area divided by Census Sub Divisions (derived from Census Canada, 2001) 
This study specifically chose to exclude East-Ottawa from its recruitment efforts for a number of reasons. First, based strictly on population data, West Ottawa has the greatest number of seniors in the city. Second, West Ottawa has a greater concentration of older seniors, which presumably translates in to greater recruitment possibilities. Next, there exist language barriers between the researcher and potential participants in East Ottawa due to a larger French-speaking population. The larger francophone population in the east end of Ottawa could further eliminate the potential subset of independent seniors aged $75+$ who would be eligible to participate in this study.

\section{Target Participants}

Ideal participants are seventy-five years and older, residents of the west-end of Ottawa as illustrated in Map 2 and/or users of local facilities (public library, YMCA/YWCA, shopping centres, community centres) within this region. Participants are divided into groups based on two characteristics: driving status and living conditions, described in detail below. Table 2 identifies the four desired focus groups in terms of participant characteristics.

\begin{tabular}{|l|l|}
\hline $\begin{array}{l}\text { Drivers } \\
\text { Living in retirement/seniors community }\end{array}$ & $\begin{array}{l}\text { Non-drivers } \\
\text { Living in retirement/seniors community }\end{array}$ \\
\hline $\begin{array}{l}\text { Drivers } \\
\text { Living independently in their own home }\end{array}$ & $\begin{array}{l}\text { Non-drivers } \\
\text { Living independently in their own home }\end{array}$ \\
\hline
\end{tabular}

Table 2: Ideal focus group categories

The distinction between drivers and non-drivers is clear; those people who are licensed and operate a private vehicle as their primary mode of transportation are considered drivers. The distinction between the two living arrangements is less clear. 
'Living independently in their own home' includes all those who reside in personally rented/owned accommodation (house, condominium, apartment), either alone or with their spouse. A 'retirement/seniors community' refers to an institution designed exclusively for seniors, providing some support services such as a dining lounge, daily programming and personal security, but not responsible for long-term health care. Seniors residing in nursing homes are excluded from this study because they do not live independently and require dedicated, ongoing care.

Seniors are divided by housing type to uncover differences in either attitude or needs between seniors who live in retirement communities and those who live independently with regards to public transit in Ottawa. This approach highlights the benefits of onsite services and immediate support provided by a retirement community setting in comparison to independent living and provides insight into how housing arrangements might change seniors' need for public transportation. For example, seniors living in retirement communities do not prepare their daily meals and therefore do not need to go grocery shopping as often as those who live independently and prepare their own meals; however seniors in both scenarios need to travel to specialist medical appointments. The conveniences of retirement community living may influence the needs seniors have for public transit, and therefore may distinguish them from those who live independently and rely either on their private automobile or community and family support as their means of transportation. Separating seniors by housing type allows this idea to be explored further. 
The distinction between living arrangements blurs under two arrangements.

The first is when a participant lives with family members and therefore may have some degree of daily support and care similar to that of a retirement community. Second is the case of seniors who reside in condominiums/apartment complexes targeted towards the elderly. These buildings often have organized social activities and tend to be located along main arterial routes, adjacent to shopping centres or strip malls with direct access to OC Transpo bus routes. These participants experience very different access to services than their counterparts who live in houses in more suburban areas. For the purpose of this research, the distinction between those residing in retirement communities and those who live independently is best made in terms of formal (paid) versus informal (unpaid) care. Seniors who live in retirement communities knowingly and intentionally pay for the support services described above, and as such, retirement community living is associated with a level of affluence not available to all seniors. Others, whether living in a house in the suburbs, with a family member, or in a high rise building, may incur greater rent or cost of accommodation by choosing a location with better access to services, do not pay for the same daily services (meal preparation, on site physician, activities) and are therefore considered in the same category. Analysis of focus group discussions will, however, consider the heterogeneous living experiences of the latter category.

\section{Recruitment methodology and description of participants}

Four focus group discussions were conducted between August 9, 2004 and September 15, 2004. A total of twenty-four seniors participated in this research, ranging 
in age from 65 to 93 , with an average age of 77 . Table 3 shows a breakdown of focus group locations, and specific group characteristics are discussed below.

\begin{tabular}{|l|l|l|}
\hline Focus Group & $\begin{array}{l}\text { Number of } \\
\text { Participants }\end{array}$ & Date \\
\hline Soloway Jewish Community Centre & 8 Women & August 9, 2004 \\
\hline Sterling Place Retirement Community & 3 Men, 4 Women & August 12, 2004 \\
\hline Somerset Towers Apartment Complex & 2 Women & August 25, 2004 \\
\hline $\begin{array}{l}\text { Participant's private residence (“Frank's } \\
\text { house") }\end{array}$ & 6 Men, 1 Woman & September 15, 2004 \\
\hline
\end{tabular}

Table 3: Focus group breakdown: locations, participants and dates

Focus group participants were found in a number of ways. First, program directors at four retirement communities within the study area were contacted directly and asked if their residents would be interested in participating in this study. One location was deemed unsuitable because its residents did not have their own power of attorney and the process of getting appropriate permission to conduct the focus group within the project timelines would be too difficult. Two other residences expressed interest in participating but did not follow through in their efforts to organize a group of residents to participate, possibly because it was summer when they were contacted and key personnel were on vacation. The program director at Stirling Place was the most enthusiastic about participating in the project and proceeded to collect a group of suitable participants and arranged for a day for the focus group to take place.

Recruitment of independent seniors followed a similar path. Program directors at four local community centres were contacted and asked if they would assist in attracting a group of seniors together to participate in a focus group. Three of the centres agreed to post signs advertising the project but were otherwise unhelpful in recruiting participants, 
stating they were either not permitted to solicit members or that they had previously tried recruiting individuals for research projects without success. The program coordinators at the Soloway Jewish Community Centre, however, were very receptive to the project and invited me to speak to members of the 'Seniors Friendship Club' to see if the group would be interested in participating during a future group meeting. The members agreed and the focus group was scheduled during a meeting three weeks later.

Approximately twenty additional posters were placed throughout the study area at the public library, on community bulletin boards in shopping malls and in the common room/foyer/laundry rooms of apartment buildings (see Appendix I). Two participants responded to a poster in their building. A final focus group consisted of neighbours from the area who meet regularly for lunch and who had heard about the study through the community and were eager to help with the project.

Gatekeepers were responsible for recruiting more than half of the individuals who participated in the focus groups, making their role in this project extremely important. Of the eight community centres and retirement homes contacted, only two gatekeepers were helpful and followed through with their commitment to recruit participants from within their communities. The main reason the other six gatekeepers did not help recruit participants was because they claimed that the seniors within their respective communities did not use OC Transpo and would therefore be of no use to my research. Despite my explanations that these seniors are equally important to the focus groups, they remained sceptical of their ability to help and therefore declined involvement in the project. 
The mood of each focus group was positive and upbeat and participants appeared happy to volunteer their time to the project. They were not financially compensated for participating but were provided with refreshments and snacks. Two groups were held during weekly social meetings, and participants seemed happy to meet with me and asked several questions about the project. Every group ended in a role reversal with participants asking for details about my plans for the future and what I would do with the results of the study. With the exception of the Somerset Towers group, participants knew each other before the focus group. This may be why they were so candid in their discussions and seemed to hold nothing back in their evaluations of the good and bad sides of public transit in Ottawa. Many strong statements of opinion were made in each focus group, reflecting ardent personalities and a wealth of experience.

Soloway Jewish Community Centre, August 9, 2004

A total of eight women participated in this focus group, all of whom are nondrivers. One woman had access to ongoing transportation provided by her son while the remaining seven were Para Transpo users. The women of this group were the oldest participants, between the ages of 72 and 93 . Participants in this group all lived either in their own home or with family, and all were widows.

Sterling Place Retirement Community, August 12, 2004

Seven participants, three men and four women, took part in this focus group discussion. All are residents at the Sterling Place Retirement Community, a facility oriented towards those who do not require permanent nursing care but prefer the security 
and convenience of an environment designed for seniors. Residents have their own private living space but share communal meals in a dining hall, have access to an onsite doctor and nurse (although many choose to stay with their own physician), have daily activity programming onsite and organized outings. All participants are non-drivers and represent the youngest participants in this study. Two participants in their early seventies are married to each other and another woman in her late seventies is married and resides with her husband (who did not participate in the study) at Sterling Place. Two other women recently moved to Ottawa, one from Cambridge, Ontario and the other from the United Kingdom; both are widows and in their eighties. Of the two remaining men, one is single and 65 having moved into the retirement community following a brain aneurysm, and the other man is a widow in his mid-seventies. This group uses a mix of OC Transpo, Para Transpo, and private and volunteer transportation services.

Somerset Towers Complex, August 25, 2004

Somerset Towers is a rental apartment building located directly beside Carlingwood Shopping Centre with seniors occupying approximately fifty percent of the two building units. Two women participated in this focus group. The first, aged 78, recently relocated to Ottawa from Lindsay, Ontario and resides with her husband. The second, an 83 year-old widow, moved to Ottawa recently after selling her condominium in Ajax, Ontario. Both are non-drivers and use OC Transpo, family, volunteer services and taxis to get around. 
Participant's private residence, 'Frank's House' September 15, 2004

The seven members of this focus group, consisting of six men and one woman, are all drivers. Two men occasionally use OC Transpo. The participants range in age from 73 to 83 . Two men are married and the other five individuals are widows. All live independently in houses throughout Nepean.

\section{Focus group questions}

Table 4 presents the questions asked at each focus group session. As previously described, the questions follow a moderately structured focus group style and the sequence of questions roughly follow a funnel structure outlined by Morgan (1998b:52). To open the discussion, the group was asked to think about the past week and identify how they get around on a day to day basis. From here, they talked about what services are available to help them accomplish their daily activities and what role OC Transpo/Para Transpo plays in that. Participants were then asked to comment on what would make OC Transpo service better and why, followed by how funds should be spent in the City of Ottawa. The second half of the focus group discussion focused on perceived quality of life. Participants were asked to talk about what adds to and detracts from their life as a whole, and then to identify what single thing would improve the overall quality of life for people their age in the City of Ottawa. The discussion concluded with a summary of the comments made during the focus group and the opportunity for participants to clarify or add to the statements they made. 


\begin{tabular}{|c|c|c|}
\hline Type & Issue addressed & Question \\
\hline Opening & Icebreaker & $\begin{array}{l}\text { Tell us your name, where you live and how you got } \\
\text { here today. }\end{array}$ \\
\hline $\begin{array}{l}\text { Introduction/ } \\
\text { Transitional }\end{array}$ & $\begin{array}{l}\text { Move towards key issue: } \\
\text { How does transit accessibility } \\
\text { impact perceived quality of } \\
\text { life? }\end{array}$ & $\begin{array}{l}\text { Think back over the past week or two. How do you } \\
\text { get around to do your shopping, get to } \\
\text { appointments, visit friends and family? }\end{array}$ \\
\hline Key & $\begin{array}{l}\text { How does access to public } \\
\text { transit and virtual mobility } \\
\text { shape perceived quality of life }\end{array}$ & $\begin{array}{l}\text { Are there services available where you live to help } \\
\text { you accomplish your daily activities? }\end{array}$ \\
\hline Key & & $\begin{array}{l}\text { Does access to OC Transpo impact your ability to } \\
\text { accomplish daily activities? }\end{array}$ \\
\hline Key & & $\begin{array}{l}\text { If you could change one thing about OC Transpo } \\
\text { what would you change, and what is the main } \\
\text { reason it needs changing? }\end{array}$ \\
\hline Transitional & $\begin{array}{l}\text { Move towards key issue: How } \\
\text { well municipal services } \\
\text { address the needs of the } \\
\text { elderly }\end{array}$ & $\begin{array}{l}\text { In recent years there has been increasing concern } \\
\text { about where taxpayers money is going and where } \\
\text { municipal funding goes. What are the most } \\
\text { important municipal services you use in the City of } \\
\text { Ottawa? }\end{array}$ \\
\hline \multicolumn{3}{|c|}{$\begin{array}{l}\text { Explain: "The following questions will use barriers, helpers and brainstormed ideas to help answer } \\
\text { questions. In answering these questions, if you think of something that helps you and makes } \\
\text { accomplishing tasks easier, we will write it on a 'helper'. If you think of things that make accomplishing } \\
\text { tasks more difficult, we will write then on a 'barrier'. If you have other suggestions and ideas, we will } \\
\text { write them on a sun as a brainstorming idea." }\end{array}$} \\
\hline Key & $\begin{array}{l}\text { How well are the city's } \\
\text { policies in line with the } \\
\text { requirements of the growing } \\
\text { elderly pop in Ottawa? }\end{array}$ & $\begin{array}{l}\text { Thinking about your life as a whole in Ottawa, what } \\
\text { is it that makes your life good, that is to say the } \\
\text { things that give your life quality? Mention as many } \\
\text { things as you like. }\end{array}$ \\
\hline Key & & $\begin{array}{l}\text { What is it that makes your life bad, that is to say the } \\
\text { things that reduce the quality of your life? Mention } \\
\text { as many things as you like. }\end{array}$ \\
\hline Key & & $\begin{array}{l}\text { What single thing, in your opinion, would improve } \\
\text { the overall quality of life for people your age in the } \\
\text { City of Ottawa? }\end{array}$ \\
\hline Summary & $\begin{array}{l}\text { Follows a brief oral summary } \\
\text { of ideas emerging from focus } \\
\text { group discussion }\end{array}$ & Did I correctly describe what has been said? \\
\hline Endi & & Have we missed anything? \\
\hline
\end{tabular}

Table 4: Focus group questions

\section{Ethical considerations}

This project obtained ethics clearance before any participants were recruited.

Prior to participation, participants were required to read and sign a letter of informed

consent (see Appendix II), outlining their rights, risks and benefits as a participant. 
Complete confidentiality and anonymity was not offered to participants, however they were informed that their full name and address would be kept private and confidential.

Risks

There were no foreseen emotional, social or psychological risks to participating in this study. In order to reduce physical and financial risks, focus groups were conducted onsite wherever possible, at locations where a group of seniors usually meet. This reduced anxiety about traveling to and finding a new location, making participation more convenient. Two focus groups (Sterling Place Retirement Community and Somerset Towers) were held onsite and participants were not required to leave their residence to participate. The remaining two focus groups (at the Jewish Community Centre and at a participant's private residence) were held during regularly scheduled weekly social meetings, again facilitating participation in the focus group by reducing inconvenience to individuals. The travel required for participation in the focus groups was representative of normal weekly travel patterns. Additionally, all public locations had free parking, were fully accessible and located on a bus route.

\section{Benefits}

Direct benefits to the participants of this study include socializing and engaging in discussion with peers in an environment designed for listening and taking note of common concerns about public transit accessibility in the local community. OC Transpo and the City of Ottawa will be given the results of this research, in hopes of heightening 
their awareness of the mobility needs of the elderly and bringing to light the impact transit planning decisions have on the quality of life of the elderly in Ottawa.

\section{Supplementary use of interviews}

Following the analysis of the focus group data, meetings with Pat Larkin, (Manager of Para Transpo), Councillor Alex Cullen (representing the study-area ward) and Councillor Clive Doucet (Vice-chair of Ottawa's Transportation and Transit Committee) were conducted throughout July 2005. Informed consent was obtained to use the results of the interviews in this research. These interviews are important because they outline what the views and opinions of decision makers and service providers are regarding seniors' access to public transportation. They illustrate the degree to which decision makers are in line with the views and opinions of seniors and whether or not there is a gap between what each side sees as important. An outline of the research objectives, a summary of focus group analysis and the following questions were provided to each individual prior to the interview in order to guide the ensuing discussion:

1. Given that Ottawa's population of seniors is expected to triple by 2031 , what can the City of Ottawa do to accommodate the transitioning mobility needs of seniors in the former municipalities like Nepean or Kanata who are at risk of becoming stranded in the suburbs?

2. From an urban planning perspective, how do you perceive the problems of an aging society?

3. From a service provider perspective (OC Transpo, Para Transpo), how do you view the problems of an aging society and the mobility issues of seniors? 
4. What do you see as the purpose of public transportation? What do you think are the priorities of public transit in the City of Ottawa?

All individuals contacted responded quickly to my request for a meeting. The tone and resulting information obtained from each interview varied greatly and is elaborated on in detail in Chapter 5.

\section{Conclusion}

Although transportation research is traditionally framed by quantitative methodology, the use of qualitative methods in the form of focus groups is a more effective means of analyzing the mobility experiences of seniors and the impact current and future levels of public transit service have on their perceived quality of life in Ottawa.

The study area represents the region of Ottawa with the highest number and highest concentration of seniors over 75; however, as Chapter 3 highlighted, the expected overall and senior population growth in Ottawa mean this distribution is likely to change in the future in favour of the former municipalities (where seniors will age-in-place) and central locations along arterial routes close to shopping and services (such as the condominium buildings seen along Carling Avenue, within the research area). The choice of study area likely influenced the experiences described by participants, and had the same questions been posed to seniors living in other areas of the city (such as Kanata or Orleans), the results could have been different. The focus group composition successfully captured a variety of opinions, experiences and circumstances of seniors with respect to public transit in Ottawa. These provide a platform from which to delve 
into the mobility challenges facing seniors and explore how public transit provision and city planners can help enhance the quality of life of seniors through their decisions. 


\section{Chapter 5: Analysis}

\section{Introduction}

Thus far, challenges faced by seniors as a result of an automobile-dominated urban form and lifestyle adjustments associated with aging have illustrated why it is important to consider the access that seniors have to different modes of transportation when speaking about their overall well-being. In this chapter, the results from focus group discussions explore how important these problems actually are to seniors in West Ottawa.

Beginning with what seniors claimed are the things that contributed to or detracted most from their perceived quality of life, the ways in which their perceived quality of life and independence are facilitated by access to public transit are presented. Next, the actual mobility challenges described by participants are identified, along with an analysis of whether or not public transit can be an appropriate tool in finding a solution to them. Transitioning mobility and how losing driving privileges changes perceived quality of life is explored. Finally, this chapter concludes with a discussion of how seniors support each other and what steps the community can take in facilitating the independence and quality of life of its senior members.

\section{Perceived Quality of Life}

When asked to describe things that make their lives better, similar responses were given by all participants, including males and females, drivers and non-drivers across all ages. The three most frequently reported answers to what makes their lives better are as follows: 
1. A social support network of family, friends and the local community

2. Good health

3. An active social life

When asked what detracted from their quality of life, the responses varied greatly by gender, housing arrangement and by ability to drive. To begin, drivers, almost all of whom are men, noted that telemarketers, door to door canvassing, "kids on skateboards", and a lack of sidewalks detracted from their quality of life. Non-drivers living in Sterling Place retirement community stated they were very content with life but that they would be better off if the crosswalk signal adjacent to their building was longer, allowing them to cross the busy street safely. While each problem described here could seem trivial on their own, the underlying tone of the discussions focused on community safety and how changes to the neighbourhood, in resident composition, increased traffic or otherwise, has led seniors to feel an eroding confidence in levels of personal and/or community safety.

Non-drivers living independently, all female and most widows, had two predominant responses to the question of what makes their lives bad and detracts from their quality of life:

1. Isolation

2. Loss of Independence

The women from the JCC group, consisting of the oldest and least mobile of all those interviewed, focused on isolation more than loss of independence, although both were mentioned during the discussion. Some described how their friends had passed away and therefore had fewer people to interact with, and also described how it was difficult to 
meet new people. Others explained that some days they just didn't feel physically well enough to leave the house because they were stiff and sore with aches and pains resulting from osteoporosis, arthritis, osteoarthritis or other medical barriers. Another woman described how she enjoyed when people called her on the telephone, because the days were long when there was no one to talk to.

Loss of independence, or difficulty in maintaining it, was at the core of the discussion with the independent, female non-drivers at the Somerset Towers focus group. The women explained that they are able to get around on foot or by bus most of the time, and that they don't like to impose on their families too often by asking them to take them out. Both women are healthy and active individuals who see their friends deteriorating and have become all too aware of the limitations that come with being dependent on others for help with daily activities. They both expressed frustration in watching their friends wait for Para Transpo, echoed by the women at the JCC focus group. As personal mobility deteriorates, walking becomes more difficult and as balance and stamina decrease, Para Transpo is the only financially sound method of getting around independently. The women at the JCC focus group provided numerous examples of how Para Transpo is paramount to their ability to get around the city on a regular basis, allowing them to get to medical appointments, weekly lunch dates and knitting circles. Para Transpo and its role in the maintaining an independent lifestyle is discussed in detail later in this chapter. 
Figure 3 is provided to summarize the findings of what adds to and detracts

from the quality of life of seniors interviewed. Following this is a list of excerpts derived from answers provided to questions $7-9$ about what makes life good, what makes life bad, and what single thing would improve the overall quality of life for people the same age in Ottawa.

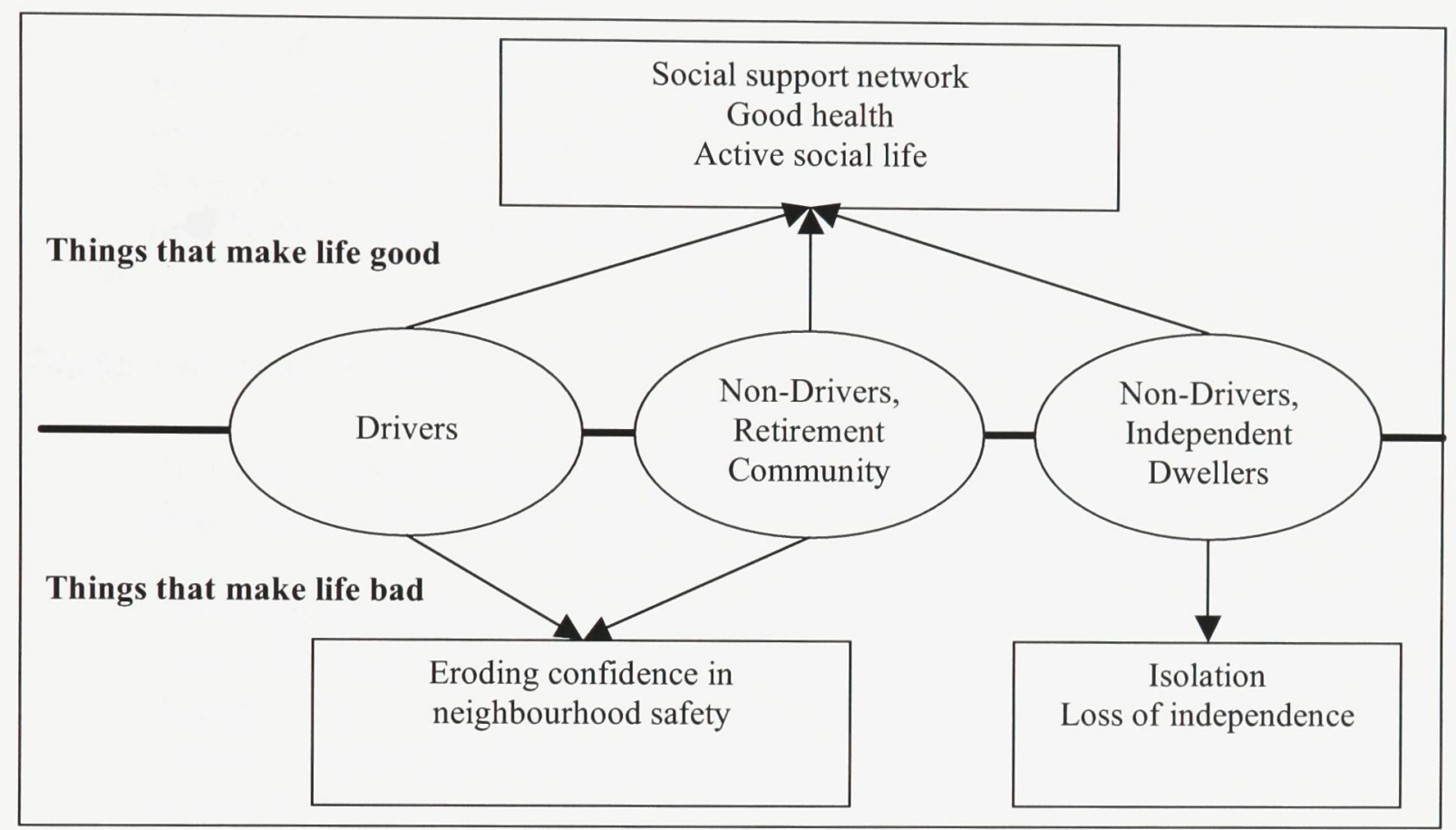

Figure 3: Summary of Quality of Life Findings

Things that make life good

"In ordinary living, neighbours are almost essential... For depth of living, I depend on my family. The third thing I depend on is what I do every day. I go into work as a research scientist and I keep that up. I love doing it. In keeping with that are the organizations I've joined. Top one is the legion, I enjoy going there and it's the best night of the week." - Bernie (81).

"I rely a lot on family. Six of them live around here. When my basement flooded, two of my sons came over immediately to help mop up the floor. My husband passed away in December, so that kind of thing panics me." - Phyllis (73).

"I think just to feel that we're part of the community is pretty important. That we're alive and kicking and doing things!' - Jean (77). 
"If my overall health were a little bit better that would be ok" - Bill (77).

"Being healthy enough to get out is the most important thing in life" - Freda (76)

"I enjoy going across the street to play bridge, having an activity is absolutely essential. And the library and shopping within walking distance." - Jessie (83)

"Our Wednesday gatherings for lunch make my life good [others agree]." - Art (80)

"The legion is a top priority for me. It's a place to go every Friday. I will walk my son's dog for exercise, stop by the legion for one beer and talk to a few guys and I think it's very important ... I went to Florida for a month and a half but I'll never go back because there was nothing to do. As long as my health is good, and I can keep up my activities, I'm happy. " Frank (83).

Things that make life bad

"Losing a sense of community or changing neighbourhoods would take away from my life. That's why I would hate to move”- Phyllis (73)

"The only problem we seem to have is the traffic lights! You can't even make it across the road. Even if you start at the right time, the lights go so fast!" Audrey (76)

"That's why I haven't tried the city bus, I'm scared of getting out there and with so much traffic I'm afraid I'll be ploughed over!' - Jean (77).

"Losing independence. Write that down in bold, it's important." - Jessie (83)

"Lack of independence. When I came here I left all my friends. I used to belong to the Newcomers Club in Lindsay Ont., and when I came here I called them up in Ottawa and was made very welcome, but if I could only get to their meetings! I can't get there because I didn't have a car." - Carmel (78)

"At one time my whole life revolved around Para Transpo, I found that they were keeping me waiting for so long and they were most irregular with timing and picking you up." - Freda (77).

"My phone might ring once a day, maybe not. If it weren't for my daughter calling me, my friends are all gone. I shouldn't complain though, I'm still here! But I like it when people call me." - Mary (93). 


\section{Linking perceived Quality of Life to transportation}

None of the aforementioned responses to what makes life better explicitly states that having access to any particular mode of transportation, private or public, has an impact on the participant's perceived quality of life. However, without transportation, a person's ability to participate in many social activities (such as the Royal Canadian Legion, Seniors' clubs, evening theatre) is hampered. Similarly, when considering what detracts from quality of life, individuals' ability to maintain their independence and overcome isolation is greatly influenced by their ability to access public or private transportation in order to go shopping, get to appointments and participate in activities outside their home. These factors, ability to participate in social activities, loss of independence and isolation and how each relates to access to transportation are discussed in greater detail here.

\section{Participating in Social Activities}

The convenience of having access to a private automobile versus relying on OC/Para Transpo as a primary mode of transportation has a clear impact on seniors' ability to participate in activities, as reliance on public transit may limit the variety of activities and locations available to them. Those who can drive have a greater choice of activities to participate in because they have the ability to get to a wider range of locations more easily. Participants who rely on the bus have a more difficult time due to scheduling and walking distance to and from bus stops. For example, participants from Sterling Place Retirement Community expressed how difficult it was to get to church on Sunday because of reduced bus service, and how difficult it was to get to and from the 
new bus station at Bayshore Shopping Centre because of the long walk. Private transportation by taxi is too expensive to be used for leisure activities, reserved only for time conscious medical appointments or emergencies, and family members are not always available through the day to drive seniors around. The difference between drivers and non-drivers and barriers to participating in activities is highlighted simply by using the process of organizing focus groups as an example.

The Somerset Towers focus group, originally to be held at the Churchill Senior's Community Centre, was conducted onsite in the residential apartment building for several reasons. First, the road in front of the community centre was under construction and regular bus routes were operating on a detour, which caused confusion for those who had never taken a bus to the location before and deterred others from participating because of the uneven terrain and longer walk to and from the bus stop. It was also difficult to organize a time when all interested participants were available. One woman who wanted to participate could not get to the focus group because she had a previous commitment and did not have enough time to catch a bus and arrive before the focus group ended.

The day of the JCC focus group, the elevator in the building broke down and participants could not climb the staircase to get to the meeting room booked for the group interview. An alternate location in a building across the street was used instead, causing a great deal of stress to six of the eight women who were expecting to be picked up by Para Transpo. Because the pick up address was different some feared they would be stranded when the driver arrived and could not find them, although Para Transpo was made aware of the changes, signs were posted with the information in case the driver did 
not receive the update and staff at the reception desks in both buildings were notified to look for Para Transpo. The participants explained that their anxiety stemmed from similar experiences where if they were not at the place indicated on the driver's information sheet, they were left behind and had to find their own way home. All participants were picked up that day with no problem; however it highlights how rigid leisure plans need to be when relying on Para Transpo as a primary mode of transportation.

In contrast, the participants interviewed at 'Frank's House' had no trouble getting to and from his private home, each with their own car. Similarly, at Sterling Place Retirement Community, the most difficult part of getting participants to the focus group meeting was finding them within the building and tearing them away from another activity they were already participating in. The participants with flexible modes of transportation had a much easier time participating in the focus groups than those who relied on OC Transpo or Para Transpo.

Loss of independence and isolation

Transportation is linked to maintaining independence and overcoming isolation. Without access to private or public transportation that they can consistently and confidently use, seniors become reliant on family and friends to take them places they want to go, or become unable to do the things they want to do. Carmel feels adamantly about the importance of OC Transpo in allowing her to get around the city:

"Being able to use transit gives us our independence. We just can't depend on our children because they're busy" - Carmel (78) 
The participants from Somerset Towers, a large residential building located directly beside Carlingwood Shopping Centre, are the only people who stated that they walk to nearby shops and amenities on a regular basis. They both explained that they use the mall on a daily basis, as a necessity, as a convenience and as a leisure activity. The building's proximity to a grocery store and other amenities was paramount in both their decisions to relocate there, paying higher rent because of the location.

The following quote emphasized the connection between housing, transportation and an individual's ability to maintain their independence:

"I owned a condo and sold it when I gave up the car. My son found this apartment (in Somerset Towers) and thought it would suit me, that way he wouldn't have to take me grocery shopping" - Jessie (83).

By living within walking distance of the amenities needed on a daily basis, Jessie is able to eliminate her dependence and in her words, burden, on her family. But as many seniors appreciate, there are simply some days she doesn't feel up to walking.

"I consider myself independent, but I have osteoporosis and osteoarthritis, and that can cause trouble. The odd day I feel as if I just don't want to walk" - Jessie, (83)

She still uses OC Transpo, family, volunteer services and taxis for other trips, but on a day-to-day basis she is able to take care of her needs without relying on others or expensive modes of transportation.

For others who either do not live near enough or feel well enough to walk to shops, Para Transpo is of utmost importance to maintaining their independence and allowing them to get out of the house. Gaining access to a door-to-door service such as 
Para Transpo can mean the difference between isolation and participating in the community.

"For \$1.80, Para Transpo will take you from one end of the city to the other. The amount for taxis is over $\$ 20$, and we pay $\$ 1.80$. For that I think we should be grateful. For some of us we wouldn't get out that often if we had to pay \$20." Helen (80)

"I come from Montreal and I was getting around there only by taxi. I couldn't take the regular bus and the only way I could go grocery shopping or go to the doctors is if I took a taxi. When I applied for Para in Montreal I was refused on the basis that I was using a cane. In Ottawa I was accepted with just a cane, and now I need a walker. The service is wonderful." - Bernice (73)

As noted in the previous section, the primary mode of transportation used by seniors can impact how easy it is to participate in community activities and therefore plays a role in overcoming isolation. This does not suggest that it is the only factor influencing the social lives of seniors, as their individual personality and inclination to participate as well as overall health certainly play a large part. However access to a private vehicle facilitates participation more so than solely having access to public transit (Para Transpo included).

While the non-driver independent dweller groups emphasized maintaining independence explicitly, it is likely an important factor to the drivers as well. Only one driver mentioned in passing that anything allowing him to maintain his independence would make his life good. Although other participants did not join in chorus the way they had in other groups, other parts of their discussion reveal similar feelings. Drivers spoke passionately about their fear of losing their drivers license, explaining it is their worst possible fate. They have a daily reliance on the automobile and to even think about losing it evokes strong emotions of anxiety and trepidation. The issues surrounding loss 
of driving privileges are presented later in this chapter in greater detail; however it is important to mention here because it shows that although not explicitly stated, drivers value their ability to maintain an independent lifestyle. Both drivers and non-drivers value the independence they have, agreeing that ability to maintain an independent lifestyle is critical to a high quality of life.

\section{Overcoming Mobility Challenges}

The following section is divided into two subsets. The first describes the mobility challenges faced by seniors who still drive, followed by the challenges faced by nondriving seniors.

Drivers

The participants who drive did not identify major mobility problems; all spoke of how content they were to use their cars to get around on a daily basis, and said they would only use public transit in certain circumstances such as an emergency or to avoid traffic and high parking fees when going downtown two to three times a year. Although participants themselves did not identify it as a 'problem', many noted they lacked confidence when driving. Two people described how they avoid driving when it is dark outside or when the weather is bad because they have difficulty seeing under such conditions; however nobody seemed to mind this and it was not identified as hindering their lifestyle.

"I'm not comfortable driving downtown. I go out to visit my kids because I know the way there, but that's it. Finding a new place-forget it! I only like to drive when I know where I'm going." Phyllis (78). 
"I avoid driving at night, especially when it's raining. I get lost and can't see the centre line on the road." John (77).

Perhaps the greatest challenge to face senior drivers is yet to come, the day they have to give up driving.

Non-Drivers

Non-drivers have a variety of alternative modes of transportation to choose from, each with pros and cons. Taxis are convenient but expensive and generally reserved for emergencies or when trips are time sensitive. Walking is a popular alternative, provided amenities are close and convenient. Volunteer groups operating grocery buses are popular with seniors residing in larger apartment/condominium buildings along arterial roads, but do not always fit into the weekly schedule and are difficult for seniors living in the suburbs to access. Family and friends are often relied upon to help transport seniors to and from appointments and shops, but schedules can be difficult as adult children have very busy lives. OC Transpo and Para Transpo each have their own strengths and weaknesses, discussed below.

OC Transpo provides inexpensive transportation throughout the day. They continue to update their fleet of buses with accessible vehicles, implementing physical accessibility plans to accommodate people with walking aids, companions and disabilities. However many of the seniors complained that they were either unable to walk comfortably to the bus stop, or if they could get there, they had difficulty standing and waiting for the bus without a chair or bench to sit on. Scheduling can also be a problem, with evenings and weekend service reduced: 
"Seniors need transit. In Ottawa daytime is wonderful, but it's reduced in the evening. Are seniors supposed to stay home after 6pm? We're not dead yet! We don't go to the theatre at night because getting home the bus service is reduced. So you wait 30 minutes. It happened to us, we got out of the National Arts Centre in November with my elderly father and we waited 30 mins and nearly froze. We don't go out at night because the service is reduced." - Carmel (78).

One couple from Sterling Place Retirement Community explained that they had friends come pick them up to attend church on Sunday because the bus only runs once an hour.

Para Transpo has a different set of pros and cons. Every senior who spoke of Para Transpo praised its drivers for the excellent job they do and how accommodating they are. Timing and scheduling are the most common barriers to using the service:

"First they told me I was phoning too soon. You can't phone until 24 hours before you need the bus. Then the next time I phoned them it was full. You can't win!" - Jessie (83).

"At one time my whole life revolved around Para Transpo, I found that they were keeping me waiting for so long and they were most irregular with timing and picking you up. The rules are that if the driver hasn't come within half an hour you must call them. Well not having a cell phone meant I had to go upstairs to the $6^{\text {th }}$ floor and phone. The driver arrived and when they came late if you weren't waiting outside they didn't wait for you. They'd drive in, you weren't there, and goodbye. While I was talking on the phone, they were downstairs." Freda (76).

"I had friends come over and play cards in an evening. One of my friends was brought here a half hour early, then picked up an hour early to go home. My other friend didn't get here for an hour and a half and we waited, and Para came back for her at 10:30pm, but we waited with her until 11 pm. I see this happenall the seniors do in their retired time is wait. Wait for buses, wait for Para Transpo, and I believe it is a major problem." - Carmel (78).

Individual experiences with Para Transpo are varied, and while seniors expressed gratitude for its availability, there really is no alternative to the inexpensive door-to-door service and many feel their frustration and criticism falls on deaf ears. 


\section{Transitioning Mobility}

Of the 24 focus group participants, 7 currently drive, 15 no longer have a driver's license and 2 have never been drivers. The following section will look at the challenges associated with losing driving privileges and the outlook for the future.

Impact of losing license

The participants at the 'Frank's House' group were all licensed drivers. They had very few comments about OC Transpo because none of them were regular users, and nobody had ever used Para Transpo. The only reasons they stated for using public transit was if they were going to the downtown core to visit a museum or attend a special event. The high cost of parking, traffic and unfamiliar streets deter these seniors from driving downtown while the relative ease of getting to specific places by bus, such as the War Museum and Parliament Hill, were cited as the reasons for taking public transit instead.

When asked how they would feel if their driver's license was taken away tomorrow, their responses were telling:

"Its like being downtown in the nude with no money. It's that bad, it's grim. When my car got hit I was without a car and was absolutely lost. I feel down in the dumps because I can't go anywhere and I have to depend on someone else." Frank (83)

"I would feel very dependent. I'd be dependent on my children and I'd hate that. I don't like buses either, I'm claustrophobic, and I don't like being locked in with everyone. If I couldn't use my car I'd phone one of my children. I wouldn't take a bus." - Phyllis (73)

"I go into work every day and if my car isn't ready [from the mechanic] I usually get a lift down. I never take a taxi or a shuttle bus from the company. I may take a taxi home but I won't take a bus." - Bernie (81).

"If I didn't have a car I'd just move downtown where everything is!" - Bill (77) 
Senior drivers, just like anyone else, enjoy the freedom and independence of the car. The drivers interviewed all live in the post-war suburbs of Ottawa and face the same obstacles as any other person living there - shops are generally not within walking distance, streets are wide and winding, there are few sidewalks, parking is free, public transit service is infrequent and bus stops can be inconvenient to walk to. It is therefore not surprising that the loss of driving privileges is seen in such a dramatic light. It would result in significant lifestyle changes, possibly even requiring an individual to move, leaving their established home, friends and community. As previously discussed, such a move and change in community surroundings can result in a dramatic shift in the individuals' perceived quality of life.

While these seniors continue to enjoy the benefits of driving, participants in each of the other focus groups have already faced the reality of giving up their driver's licenses. Those without a license expressed loss and frustration over the lifestyle transition to not driving. It is described as difficult and seriously impacting the daily activity patterns of participants. Many explain that it hasn't sunk in yet that they are no longer able to drive. The group at Sterling Place community centre lamented the days they sold their cars, one commenting that she had "shed a few tears over that one". At Somerset Towers, similar comments were made:

"I drove up until last fall and this is my biggest problem, it's hard now... it was so much easier and so much more fun when I could drive." - Jessie (83).

"I never drove, I had a license but I was a nervous driver and let my husband do the driving. He gave it up at 80 (in March 2004), but I miss it to go out on drives in the country, go to towns, festivals, fairs. Your independence is gone, that's where it starts... and I can only ask the kids so much (to drive us around), 
because they are raising grandchildren! I have great grandchildren, my kids are busy!" - Carmel, (78).

Of the participants who live independently and do not drive (Somerset Towers and JCC focus groups), 5 of 10 said that where they lived was an important part of their ability to accomplish daily activities. They described their decisions to live in particular places because of proximity to nearby shops and services that allows them to walk places. Only one woman clearly stated that she gave up her car at the same time she decided to move to a new home within walking distance of shops; the others did not specify whether or not they moved because they could no longer drive or for other reasons.

"There were other places we could have lived that would be cheaper, but the difference in rent would quickly be eaten up by the inconvenience of taking a bus to get groceries etc. We are fortunate to be [at Somerset Towers]. If you lived in other apartments across the city it would be different" - Carmel (78)

"I walk as far as TD Bank, about 5 blocks, but I don't walk back. I will walk to the bank, then back to the produce store (about 1 block) and then I have to take the bus home because by this time I'm carrying parcels." - Jessie (83).

"I owned a condo and sold it when I gave up the car. My son found this apartment (in Somerset Towers) and thought it would suit me, that way he wouldn't have to take me grocery shopping" - Jessie (83).

In general, driving is not completely replaced by another mode of transportation.

As described, some people will walk to nearby services. Other non-drivers explained that they sometimes have their groceries delivered (for a small fee) or they use the community grocery bus operated by the Old Forge, a community group focused on the needs of local seniors. They rely on family and friends to take them shopping and to appointments, volunteers, Para Transpo, OC Transpo and finally, but less frequently than other modes, taxis. 
Women described Para Transpo to be the most frequent and important replacement to the car, but support from a social network of family and friends supplement this. Community grocery van service is used if/when convenient but is generally not the only or primary means of getting out to buy groceries. Taxis are used for trips with stricter timelines, such as medical appointments. Walking was only stated as a means of transportation/accomplishing tasks (as opposed to purely recreational) when shops are nearby, particularly at the Somerset Towers group where Carlingwood Shopping Centre is directly next door to the building. Participants stated that any distance farther than 5 blocks in one direction would be too far to walk, because of heavy loads to be dragged back on the return trip in a shopping cart.

The JCC focus group, all female non-drivers and the oldest participants of this study, are the greatest users of Para Transpo. Eight live independently and one lives with family members. Without Para Transpo most would not be able to attend the 'Friendship Club', weekly organized lunchtime get-togethers that were described by many to be the highlight of their week.

"I feel better if I go out. In order to get here [the JCC] and a couple of other places through the week, I need transportation. Most of us don't have that much to do on Monday, but having a steady appointment for lunch is a simple thing but you do get out and you do feel better." - Helen (80).

Jessie (83) recently moved to Ottawa from Kingston, Ontario to be closer to her family. She describes her use of public transit "in a pinch", and has limited knowledge of the area's bus routes: "I don't know where I'm going. I know Lincoln Fields is where I get the bus if I want to go out of town, that's it". When asked about taking OC Transpo or Para Transpo, she responded: 
"I don't... for the most part I just don't go out. But I have a son and two grandsons living in Ottawa and if I'm stuck [I'll call them]. But both my grandsons work, and my son is retired but he spends 2 months in the summer time at the East coast, so I don't have him in the summer. Occasionally I take a cab, or call a volunteer service where you can get a driver." - Jessie (83)

Temporal outlook on driving:

Those who currently drive feel strongly about how vital it is to their lifestyle.

There is an understanding that the privilege of driving could be taken away at any moment, specifically for unexpected health reasons. They anticipate the transition will be difficult; however focus group discussions indicate that there are no provisions or advanced planning being made in anticipation of driving cessation, and the prevailing attitude appears to be "we'll figure it out when we have to".

One step in this transition that has been acknowledged by some drivers is their difficulty driving in certain conditions, i.e. in heavy traffic/downtown, in unfamiliar areas, at night, in bad weather.

"I don't consider myself a good driver. I didn't learn to drive until I was 42 and so I don't have the confidence. If I were to go downtown or to the east end I would probably get lost driving. I'd have to check a map on the way there and get lost on the way home. I'm not comfortable driving downtown." - Phyllis (73).

One participant explained that his younger wife is a better driver than him and therefore she acted as principle driver on trips under the aforementioned conditions. The convenience of being able to drive at any time and having total freedom to go anywhere in a personal automobile may be hampered as a person loses confidence or as their eyesight worsens, but they remain licensed drivers. They adapt and continue to use their vehicles during the day, recognizing that being able to drive some of the time is better than never. 
Whereas other problems of old age are anticipated and planned for (i.e.

retirement income \& savings), driving cessation is not fully acknowledged. Based on the attitudes expressed by both drivers and non-drivers, there was little or no planning made to anticipate this transition.

\section{Supporting each other}

As a researcher, one of the most rewarding outcomes of the focus groups was witnessing the information sharing and learning going on within each session. Participants not only expressed their opinions and views about public transit and their daily lives, but they listened to each other and appeared to be learning from each others' experiences, sharing their triumphs and common gripes. In three of the four focus groups the participants already knew each other, but in the case of the Somerset Towers session, the two women, both relative newcomers to Ottawa, had become friends by the end of the interview. In answering questions they problem solved together. They exchanged information on which community groups offered grocery bus service on which days, which seniors' centres were the easiest to get to and had the best value for their membership, how to use the O-Train, and how they could split taxi fares to make their common interest of going to the theatre more affordable.

Problem solving and information sharing existed in the focus groups where people knew each other. The JCC focus group discussion involved information exchange about the use of Para Transpo - how often bookings could be made, how the installation of a telephone in the lobby of condominium buildings was a great asset in case Para Transpo was late (and therefore you didn't have to go back up to your apartment to call 
and inquire about your booking and risk missing the driver all together). Residents of Sterling Place Retirement community explained to Jean, a newcomer to Ottawa, how best to get to local shops and malls by conventional transit, and how to use Para Transpo.

What this suggests is that advertising services tailored to seniors, such as a community grocery bus, organized day trips, accessible public transit and Para Transpo, are helpful, needed and worthwhile. Word of mouth spreads amongst friends and useful services will be more widely used as they become more publicized. This is particularly important given new initiatives made by OC Transpo to increase the accessibility of conventional transit, offering a variety of services such as new low floor kneeling buses, free fares for passengers with mobility devices or free fares for companions. These perks are of no use if the intended audience doesn't know they exist, as was the case for many of the focus group participants. Newcomers to the city need to be considered regarding their special circumstances, especially given the growth projections of newcomers described in Chapter 3 - they are unfamiliar with the city and may require orientation before they will use public transit. Participants were informed by their peers during focus groups as to what services are available to seniors in the neighbourhood, how public transit/Para Transpo works, how much it costs, and what social activities are available to facilitate making new friends. Seniors' centres (Carlingwood Shopping Centre, Churchill), the Old Forge and Good Companions are important points of contact in the peer social networks of seniors. 


\section{Limitations of focus group}

There are limitations to the information obtained from the focus group and subsequent results of this study. First, all data were collected during the summer months. In a city like Ottawa with cold winter weather, snow storms, ice and treacherous sidewalks, focus group participants may not have considered the difficulties they face in accomplishing daily activities throughout the winter months. Next, the seniors who were targeted for this study do not by any means represent a cross section of the elderly population across the entire region of Ottawa-Carleton. The results obtained through this study are a reflection of the attitudes and experiences of those who use the facilities of Ottawa-west and parts of the former City of Nepean, a well established area of the city with multiple commercial and residential land uses and a variety of housing choices. Results might have been very different if participants had lived in outlying residential suburbs (such as Barrhaven and Kanata), or if they had lived with extended families.

\section{Meetings with city officials}

Chapter 4 outlined the questions posed to Para Transpo manager Pat Larkin and city councilors Alex Cullen and Clive Doucet. Formal responses to these questions were not provided, but instead the topics and ideas they presented were discussed throughout each thirty to forty minute interview. Responses varied, reflecting the perspectives each had into the topic, and are described below. 
In meeting with Para Transpo, Mr. Larkin was quick to point out that the service is intended to serve the disabled community, not seniors, and that they do not view aging as a disability. Priority is given to individuals going to medical appointments (e.g. kidney dialysis), followed by passengers in wheelchairs and then to all other requests. The quantity of service provided by Para Transpo has not increased since the midnineties when their budget was frozen, however huge investments in conventional transit have made OC Transpo a more accessible system in hopes of accommodating increasing numbers of passengers with varying degrees of disability. As he explained, their bottom line is budget, and in order to get the 'best bang for your buck', investment strategies are holding back on Para Transpo in favour of increasing the accessibility of conventional transit. They anticipate that once conventional transit is fully accessible, more trips will be able to be taken by OC Transpo rather than by Para Transpo, and that seniors will be able to use it more easily and more frequently. This will result in a better-integrated public transit system in Ottawa, however they don't expect demand for Para Transpo to decrease in the future. Trends are showing that Para Transpo trips are becoming longer (citing examples of trips between Kanata and Barrhaven) and they are exploring new trip pricing options and possible reintroduction of tele-transpo service (where passengers in designated areas near a fixed transit route that exhibit lower-usage patterns can call OC Transpo and have the driver deviate from the regular route and pick them up) on some OC Transpo routes. 
Addressing issues of convenience and ease of use, Mr. Larkin cited that there is a difference between individuals who were fully functional and have become disabled and do not want to take fixed route transit and those who have always been disabled and would prefer to take fixed route transit. In his example he described the scenarios in terms of ability/disability, but supplemented with an example where age was a key factor. He stated that many seniors feel Para Transpo is easier to use than fixed route transit and they will not take the regular bus because of preconceived ideas of what the bus is like (unsafe, difficult to use, hot). In contrast he provided an example of a younger male passenger, featured in their advertising campaign, who uses a wheelchair and has no trouble navigating the city by bus every day. The reality of the situation is that Para Transpo is a system designed to have floating pick up times (resulting in up to half hour wait) and a built in refusal rate (4-5\%); the result of this design is that Para Transpo is not always the most convenient form of transportation for the passengers it serves. As Mr. Larkin's example illustrates, individuals who can navigate conventional public transit despite disabilities could find their trips easier to make. However, when age becomes a factor, the trade off between long wait times of Para Transpo and the perception of OC Transpo (accurate or otherwise) needs to be considered. There are educational, physical accessibility and route network hurdles to overcome before the City of Ottawa will be able to convince its seniors that public transit has changed from what it was twenty years ago. 
Councillor Alex Cullen (Bay Ward)

Councillor Cullen represents the ward with the greatest number of seniors in the City and is therefore keenly aware of the aging population. He admits that the City is in its "early days of planning and policy" regarding aging and transportation. He, like Pat Larkin, was quick to point out that aging is not a disability but that the incidence of disability increases with age. He stated that the high cost of Para Transpo (approx. \$15\$25 per one-way trip) and the aging demographics have fuelled the increased investment in accessibility on OC Transpo (approx. $\$ 4$ per one-way trip). Ottawa is addressing costeffectiveness problems of public transit by investing in accessible conventional transit. This is seen as a proactive solution to dealing with anticipated increasing demand for Para Transpo service.

Councillor Cullen highlighted that the transition away from driving is a public health issue. The loss of mobility can accelerate decline, and therefore there is a connection between transportation that enables individuals to be more active and their overall quality of life and health. He also stated that winter is especially difficult for seniors in Ottawa, due not only to the cold weather but the ploughing and maintenance of sidewalks and roads. The physical infrastructure and maintenance that causes an individual no trouble in the summer can seriously impede their mobility during the cold months.

Councillor Cullen made a final comment about his experiences talking to seniors about public transit, stating there is concern for security and personal safety when riding the bus. Some claim they will not attend evening meetings because there are fewer 
people riding the bus after dark and this makes them uncomfortable. In contrast, issues surrounding safety and security while riding the bus were not raised during the focus group discussions even though participants were directly asked these questions at some point throughout each session. This is likely due to the fact that the seniors who participated use Para Transpo more frequently than OC Transpo, and those who do use OC Transpo stated they tended not to use the service at night because of scheduling problems. Regardless, the vulnerability of seniors, which oniy increases with age, is a key concern when addressing the public transit needs of seniors.

Councillor Clive Doucet (Vice-Chair of Ottawa's Transportation and Transit Committee)

Councillor Clive Doucet explained the bulk of public transit resources are dedicated to commuter passengers, that the needs of seniors are secondary to commuters, and that the Transportation Master Plan is focused on peak demand in order to decrease the need to build new commuter highways. He had very little to say about the need seniors have for public transit, but instead spoke about how the integration of light rail and conventional transit would help create an "integrated hub and spoke system" to accommodate both local and commuter transit services.

The frankness and honesty of the discussion with Councillor Doucet was a welcomed surprise, and he and his staff expressed interest in the findings of this research and in exploring how the aging population will use public transit in the future. As the meeting with Councillor Cullen revealed, the City is still in its primary stages of planning for seniors in the transportation arena, clearly reflected by the comments of this meeting. 


\section{Summary of analysis}

The results of this analysis show that participants value the support network provided by their friends, family and neighbours, good health and an active social life. Independent dwelling non-drivers felt that isolation and the loss of independence were the greatest detractors to their quality of life, while others felt it was the shift in community dynamics and personal safety that most threatened their quality of life.

The values identified as adding to or detracting from the perceived quality of life of seniors are linked to their ability to access different modes of transportation. Drivers have greater flexibility to participate in community activities than do non-drivers, who rely on inexpensive but rigidly scheduled transit service, the generosity of family and friends, or more expensive taxi rides to get them to such events. Similarly, the desire to maintain independence and overcome isolation as described by non-drivers, is hampered by their lack of drivers license. Walking is generally only an option available to seniors who knowingly choose to relocate to an area in close proximity to shops and services, but is still only used when walking distances are short and parcels are light. The additional cost of living in such a location is seen as a small price to pay for the ability of some participants to maintain their independent lifestyle. In the eyes of the oldest participants who also experience the greatest difficulty in personal mobility, Para Transpo means the difference between staying home and being able to get around the city and participate in activities.

The non-driver participants are by no means captive to public transit. They have access to variety of alternatives to public transit, but maintain a preference for public 
transit in certain circumstances. Price is the most important reason why non-drivers use public transit, particularly Para Transpo, because the same trips made by other modes of transportation (such as taxi) become very expensive. Seniors are willing to pay this premium for time sensitive trips such as medical appointments, but will sacrifice recreational trips without access to public transit because the cost is too great. Given that an active social life is one of the top three factors participants saw as contributing to their quality of life, this potential elimination of recreational activities due to a lack of affordable transportation may have negative effects. Para Transpo is viewed as the most important mode of transportation available to non-drivers because it is inexpensive and provides door-to-door service. Although OC Transpo is the same price, scheduling problems (nighttime, Sunday reduced service), walking distance to bus stops and a lack of seating while waiting deterred non-drivers from using this service as frequently.

Losing a drivers license is a traumatic event for seniors. Those who have already dealt with this challenge face difficulties aging-in-place and some move to a new location closer to amenities in part as a way of coping and maintaining independence. There are, of course, a variety of reasons behind an individual's decision to move - such as declining health, downsizing property size or difficulty maintaining property - however loss of a drivers license simply adds to the difficulty of remaining independent when aging-in-place. Those seniors who are still drivers understand their situation may change in the future, and that it will result in significant lifestyle changes, but otherwise make no efforts to plan for the transition. Finally, participants learned from each other during the 
focus group discussions, pointing toward the need to advertise and educate seniors of the services available to them.

Having analyzed the results of the focus groups, there is a link between the transportation options available to seniors and the lifestyles seniors lead. The individuals themselves may not explicitly recognize this link in the way they do between their health and quality of life, but it is still significant. Drawing upon the transport planning challenges of automobile-dominant cities, the challenges inherent in aging and the results of this analysis, the final chapter presents the key findings and addresses why evaluating seniors' perceived needs of public transit is important to planning the future of Ottawa's public transit service. 


\section{Chapter 6: Results and Discussion}

\section{Introduction}

Chapter 1 outlined three questions that this research addresses. First, how necessary is an affordable, accessible public transit system in the eyes of senior citizens? Will they want to or be able to use public transit if they can no longer drive? And finally, do the oldest seniors, seen as most vulnerable to the challenges of aging, feel having accessible public transit enhances their quality of life? The answers to these questions are discussed here drawing upon the analysis and results presented in the previous chapter.

As raised in the discussion of the drawbacks of focus groups, the analysis and conclusions drawn from the focus groups cannot be used to generalize about all seniors across Ottawa; instead, the findings presented below highlight the usefulness of conclusions obtained through qualitative analysis and identify areas for further investigation and consideration on the part of planners and city decision makers.

\section{Discussion of key findings}

The analysis of the focus group discussions illustrate three key points regarding the links between aging, public transit and quality of life. First being the access that individuals have to different modes of transportation directly impacts elements they describe as being crucial for maintaining their quality of life. Individuals did not explicitly state that transportation increases their quality of life, but instead explained that they enjoy participating in community activities, and that isolation and loss of independence detract from their quality of life. These are directly impacted by the 
individual's ability to access transportation (either by private automobile, public transit, family, etc.).

A second key finding is that seniors don't plan for life after driving. Those who no longer drive express frustration over the loss of driving privileges and explain that their lifestyles have changed since they stopped driving. Drivers, on the other hand, recognize that their ability to drive may change in the future, perhaps even suddenly due to medical reasons, but generally do not plan for the eventuality of driving cessation. This may be attributable to the fact that driving cessation is not a certainty for all seniors, but there are implications for this lack of planning. First, there may not be a strong, collective voice or opinion expressed by senior drivers regarding public transit decisions and expenditures. As the population ages and seniors have increasing political clout, the lack of interest and planning for life after driving may be problematic in an arena where the loudest voices are heard and result in action. If they are not concerned with accessible public transit, they may be left with greater problems in the future if accessible systems or Para Transpo do not exist. Second, recognizing that seniors themselves do not look to the future beyond the car makes research like this even more important as it highlights the impact that not having a license has on seniors' quality of life. This research highlights the need for a proactive approach to maintaining well-being for seniors through city planning and represents their future voices, even if they don't yet realize what public transit service may mean to their daily lives.

The third key finding is that senior non-driver transit users, particularly the oldest ones, prefer the service offered by Para Transpo to conventional transit. Given that 
Ottawa does not intend to increase spending on Para Transpo service and instead to accommodate the growing need for accessible public transit via the conventional system, city planners need to understand why this preference exists in order to educate seniors about how transit is changing. Transit service will continue to change over the coming decades and seniors need to be made aware of the evolving accessible service provided by OC Transpo. If older passengers are expected to use OC Transpo instead of Para Transpo, the city will need to focus resources on training and educating them about how to use conventional transit, as well as customize certain aspects of service toward them (e.g. use of tele-transpo, more localized routes, shuttles).

Returning to the original questions posed in chapter 1, drivers who participated do not view an affordable, accessible public transit system as crucial to their lifestyle and non-drivers who participated currently see Para Transpo as more important to them than conventional OC Transpo service. As for whether or not they will be able to use transit once they are no longer able to drive, it is difficult to generalize because of the diversity of needs and abilities of seniors. In retrospect, it would have been helpful to ask specific questions about why participants had lost their driver's licenses in the first place. I believe that most seniors will transition from driving to requiring a door-to-door service like Para Transpo and be unlikely to use regular OC Transpo after they stop driving. My reasoning is twofold. First, drivers are likely to be living in their own home, which given the spatial distribution of seniors across the city, will increasingly be located in suburban neighbourhoods (as opposed to the downtown core). If they wish to remain in their home after losing their license, which the literature presented in Chapter 3 suggests is the case, 
access to conventional transit service would probably be limited in terms of scheduling and be potentially difficult for them to use. This difficulty stems from the same reasons that resulted in the loss of their license - the same visual, cognitive or physical problems that prohibit them from driving may also keep them from being able to learn a new bus system, walk to and wait for a bus (in the heat, in the cold), transfer at an intermediate station, and so on. The final question posed in chapter 1 asked if the oldest seniors, most vulnerable to the challenges of aging, feel that having access to public transit enhances their quality of life. Based on the focus group discussions, the oldest non-drivers certainly rely on Para Transpo to take them out to social meetings on a weekly basis and therefore such a service is seen as enhancing their quality of life. Drivers on the other hand, even in their eighties, only use public transit three to four times a year and do not indicate that its existence significantly alters their quality of life.

This research suggests that driving status has a greater impact on individuals' perceived quality of life than does their living arrangements. None of the participants stated their current quality of life was poor, but non-drivers described the transition from driving as being difficult and significantly changing their lifestyle; drivers did not describe any similar event causing the same degree of change in their lives. This highlights the resiliency and ability of individuals to adapt to changes in their daily arrangements when they lose their license, and that a significant decrease in perceived quality of life resulting from the loss of license is likely to be only temporary as the individual learns to cope with new routines. The presence of public transit, particularly 
Para Transpo, is then useful for enhancing non-drivers' quality of life by providing them with new transportation alternatives.

\section{What is the purpose of public transportation?}

Following the meetings with city representatives, it became clear that different people have different conceptions of what the purpose of public transportation is. The way it is defined shapes actions taken by the city regarding transit service. Is it a tool for curbing peak-hour traffic congestion and therefore a commuting alternative to the car, or is it public service allowing a captive audience, consisting of those who do not have access to a personal automobile due to lack of income, loss of license or disability, to move about the city to accomplish daily activities? These suggested purposes are by no mean an exhaustive list, nor are they mutually exclusive, but their foci are clearly very different.

If the reduction of traffic congestion were the primary purpose of public transit in Ottawa then resulting growth and funding of its transit system would focus on developing of high speed transit corridors (i.e. Transitway, proposed and existing light rail) and moving people between residential suburbs such as Kanata, Orleans and Nepean South and the downtown core. Currently, feeder routes in the morning and afternoon ('peak' or 'express' routes) operate by bringing riders to a major hub station and then proceed to take passengers to the downtown core by one of 3 major bus routes $(95,96,97)$. The timing of these feeder routes is critical to this setup, in that they only operate in one direction, i.e. towards the hub in the morning and away from the hub in the evening, thus 
coinciding with the peak flow of passenger traffic traveling to and from work. This is an example of a hub and spoke system.

In contrast, a system focused on providing a wider public service to a captive audience would be more concerned with ensuring transit links are in place to connect people to the places they visit most often: work, shopping malls, grocery stores, recreational facilities, friends and family. Given the current system, this can be difficult; Councillor Cullen highlighted this when he made the point that it is easier to get from North Kanata to downtown Ottawa than it is to get from North Kanata to South Kanata. While this highlights the need for a fully connected bus network (in contrast to the hub and spoke model described above), this research has shown that senior transit passengers still may not use such a service due to other accessibility barriers. With respect to nondriving seniors, specialized door-to door services provided by Para Transpo is preferred and more useful than conventional OC Transpo service.

Is one of these 'purposes' more important than the other? It all depends on your perspective. This research simply highlights an additional consideration to be used when making decisions about the future Ottawa, clearly growing economically but at the same time aging significantly. Is a fully connected network that directly connects every node in a network to each other the most economically efficient method of operating a public transit network? No. Is a hub and spoke transit system, a configuration most often used to accommodate daily commuters socially equitable with respect to the needs of off peak passengers whose trips do not take them to central employment areas? No. Is there common ground? Yes, but where is it and who will protect it? As pressure mounts to 
increase transit ridership by pulling people away from their cars in efforts to increase environmental responsibility, there is a risk of environmental sustainability and economic interests steamrolling social ones. It is important to recognize and protect the important social purpose that public transit serves not only to seniors, but also to an entire captive transit audience.

\section{Making accessible transit more useful}

Accessible public transit must incorporate two elements. First it requires a physically accessible infrastructure, including vehicles and built environment (low curbs, ploughed and safe sidewalks, bus shelters, benches, etc.) amenable to individuals who have difficulty getting around due to physical mobility limitations. Second, transit systems need to take individuals where they want to go. Without this connection, even the most accessible city-wide infrastructure is of little use to seniors (or other individuals) if they cannot get to and from the locations they want to go.

As the population continues to age in the former suburban municipalities, noncommuter trip characteristics may change (with greater emphasis on local off-peak trips, adjacent neighbourhood trips, and so on) and require a closer look at how the current transit network in Ottawa links people to places. There are two questions Ottawa transport planners must ask about the city's strategy of investing in accessible conventional public transit and its ability to accommodate growing number of seniors. Is the accessibility of the route network, incorporating the vehicles, sidewalks, bus stop infrastructure and safety features enabling individuals to use public transit, and is the coverage of the route network, that is to say the connectivity of the system, meeting the 
changing needs of passengers? Both these elements of accessibility need to be addressed, and as Chapter 2 pointed out, Ottawa currently is moving toward accessible infrastructure accommodating commuters, a route network that has difficulty facilitating non-peak trips.

Para Transpo is generally preferred over regular bus service by seniors without a driver's license, attributable to both physical/environmental barriers and scheduling/network connectivity limitations associated with conventional transit. Given the significantly higher cost per trip on Para Transpo, the growing aging population, resultant expected increase in demand for Para Transpo service, and the funding freeze on Para Transpo, this preference is quite problematic. Moreover, given that the City is relying on conventional transit to accommodate growing demand made by passengers with personal mobility problems who do not qualify for Para Transpo (as stricter qualification standards will be implemented to keep demand levels in check with service availability), why seniors prefer Para Transpo must be understood before the city can accommodate them with conventional transit. It is hoped that this research has shed light on why seniors make the transit choices they do, and helped to inform city officials of the importance of meeting these needs using whichever system they choose.

\section{Areas for further research}

The shifting values and emphasis on sustainability, environmental responsibility and decreased dependence on the car seen in recent years may shift the views future seniors hold regarding their willingness to use public transit. The tendency of senior drivers to use their car exclusively while they are licensed drivers may change if citywide 
driving disincentives are implemented (i.e. higher cost parking, higher gas prices) and their recognition of the need to reduce the number of trips taken by car grows. Their modal choice for trips may further influence the need for and use of public transit in the future. Therefore the extent to which choices of future seniors will be influenced by these ideals and resulting policies is an area worthy of future investigation.

The use of qualitative methodology to investigate people's behaviour and use of transportation systems is another area worthy of additional investigation. Understanding how to combine qualitative and quantitative analysis to deepen our understanding of the modal choices people make and the factors influencing their behaviour may be useful in the future as cities aim to implement additional strategies and policies to decrease dependence on the automobile.

If the challenges of aging and accessing public transportation are difficult for seniors living in urban cities such as Ottawa, those residing in rural townships face an even greater struggle. Investigating the ability of rural seniors to maintain a high quality of life given the lack of transportation alternatives available to them once they no longer drive is therefore of paramount concern.

\section{Conclusion}

The results of this research go beyond finger waging, telling planners what seniors want and subsequently recommending plans be scrapped or continued. Understanding the views held by seniors about public transportation are important because it helps planners anticipate the hurdles to getting seniors to use public transit, and helps them understand the type of service best suited to the needs of the aging population. 
Specifically in Ottawa where transport planners wish to shift passengers away from costly Para Transpo service and accommodate them instead using conventional transit, understanding why seniors prefer Para Transpo and learning about the knowledge gap between seniors' perceptions of the public transit system and the reality of its daily operation will help the City focus educational campaigns and tailor service to the needs of seniors. In doing so, the City can be more effective in its efforts to enhance the quality of life of the oldest segment of the population. 


\section{Appendix I: Recruitment material}

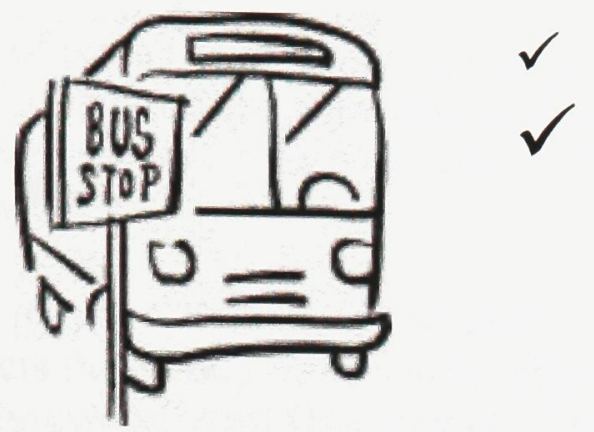

Are you over 75 ?

Do you have an opinion to share about how access to transportation affects people your age?

Volunteers are needed to participate in a research study about seniors' mobility in the Carlingwood/West Area of Ottawa.

You will be asked to discuss open-ended questions about bus service in Ottawa and how access to any transportation impacts your quality of life.

Discussion will take $1-1 \frac{1}{2}$ hours. Refreshments will be served.

Drivers and non-drivers are equally important to this study!

Location:

Churchill Senior Recreation

Centre

345 Richmond Road
Date:

Wednesday August 11, 2004 (if unsuitable, new date may be arranged)

For more information or to participate, please contact:

Kate Mullen

867-7483

M.A. Candidate in Geography, Carleton University 


\section{Appendix II: Letter of Information and Consent}

I agree to participate in this research project, "The role of public transit accessibility in the independent elderly's perception of quality of life", conducted by Kate Mullen from the Department of Geography at Carleton University, under the supervision of Iain Wallace, Department of Geography, Carleton University.

The purpose of this research study is to find out how access to public transportation affects the quality of life of the elderly seventy-five years and older in the Carlingwood/West Ottawa area. This research is undertaken as part of a Masters Thesis.

Participation in this study is voluntary.

Participation in this study will involve attending one ninety (90) minute focus group $<$ onsite/at community centre TBA $>$. During this meeting, I along with four to seven peers from my community will be asked to discuss open-ended questions about my feelings of public transit accessibility and the impact it has on my quality of life. Beverages and light snacks will be provided.

The discussion will be recorded on audiotape, and I am free to decline answering any questions. Should I exercise my right to withdraw I will decide at that time if the research may or may not use the information I have provided to that point.

There is no foreseen risk to participating in this study. Participation may not result in direct benefit to me, however results will be shared with OC Transpo and the City of Ottawa at the conclusion of this study.

The information you share in the focus group will not be confidential. You will also not be asked to share any private information. Personal information, audiotapes and transcripts of focus group discussions will be accessible to Kate Mullen only and will be destroyed (computer files deleted, paper copies shredded, audio tapes will be recorded over) at the conclusion of this study in April 2005.

Formal written results of this study will be available on request at its conclusion in April 2005 . To obtain a copy, please contact Kate Mullen by telephone at 867-7483.

I may contact Kate Mullen (principal researcher), Iain Wallace (supervisor) with any questions about this study. Please contact Kate directly by telephone if I no longer wish to participate in this study. 
The Carleton University Research Ethics Committee has reviewed this project and any concerns or complaints about my involvement in this study can be directed to their office listed below.

\begin{tabular}{l|l|l} 
Kate Mullen & Iain Wallace & Fran Klodawsky \\
Department of Geography & Department of \\
Carleton University & Geography \\
B441 Loeb Building & Carleton University \\
1125 Colonel By Drive & B440 Loeb Building \\
Ottawa, ON & 1125 Colonel By Drive \\
K1S 5B6 & Ottawa, ON \\
& Tel: 520-2600 ext. 2575 & K1S 5B6 \\
& Tel: 520-2600 x 8689
\end{tabular}

Prof. Antonio Gualtieri, Chair

Carleton University Research Ethics Committee

Office of Research Services

511A Tory Building

1125 Colonel By Drive

Ottawa, ON

K1S 5B6

Tel: 520-2517

ethics@carleton.ca

Signature of Participant

Date

Kate Mullen, Principal Researcher

Date 


\section{References}

Abeles, Ronald P., Helen C. Gift and Marcia G. Ory (Eds.) (1994). Aging and Quality of Life. New York: Springer Publishing Co.

Alsnih, R. and D.A. Hensher (2003). "The mobility and accessibility expectations of seniors in an aging population," Transportation Research Part A: Policy and Practice, 37(10): 903-916.

Atchley, R.C. (1989). “A continuity theory of normal aging," Gerontologist 29(2): 183 -190 .

Auger, Jeanette A. and Diane Tedford-Litle (2002). From the inside looking out: Competing ideas about growing old. Halifax: Fernwood.

Aultman-Hall, Lisa, Matthew Roorda and Brian W. Baetz (1997). "Using GIS for evaluation of neighbourhood pedestrian accessibility," Journal of Urban Planning and Development, 123(1): 10-17

Barbour, Rosaline S. and Jenny Kitzinger (1999). "Introduction: The challenge and promise of focus groups," In: Barbour, Rosaline S. and Jenny Kitzinger (Eds). Developing Focus Group Research: Politics, theory and practice. Thousand Oaks California: Sage Publications.

Black, William R. (2001). “An unpopular essay on transportation,” Journal of Transport Geography 9: 1-11.

------ (2003). Transportation: A Geographical Analysis. New York: Guilford Press.

Bohland, J.R. and D.T. Herbert (1983). "Neighbourhood and health effects on elderly morale," Environment and Planning A 15: 929-944.

Bunting, T. and P. Filion (Eds) (2000). Canadian Cities in Transition, Toronto: Oxford University Press.

Bunting, T., P. Filion, and L. Gertler (2000). "Cities and Transition: Changing patterns of urban growth and form in Canada", In: Bunting, T. and P. Filion (Eds).

Canadian Cities in Transition, Toronto: Oxford University Press: 1-24.

Buttimer, A. (1969). "Social Space in Interdisciplinary Perspective," Geographical Review 59: 416 - 426. 
Cavan, R.S., E.W. Burgess, R.J. Havighurst and H. Goldhamer (1949). Personal adjustments in old age. Chicago: Science Research Associates.

Chappell, Neena L. (1992). Social Support and Aging. Toronto and Vancouver: Butterworths.

Che-Alford, J. and K. Stevenson (1998). "Older Canadians on the move," Canadian Social Trends, Spring: 15-18.

Church, Richard L. and James R. Marston (2003). "Measuring accessibility for people with disability," Geographical Analysis 35(1): 83-96.

City of Ottawa (2003a). A Winciow on Ottawa 20/20.

http://ottawa.ca/city_services/planningzonging/2020/index_en.shtml

City of Ottawa (2003b). Transportation Master Plan. http://www.ottawa2020.com

Commuting Survey (1998) The Economist, September $5^{\text {th }}: 3-18$.

Cooley, C.H. (1974). "Chapter 1, Selection 2: The theory of transportation” In: Hurst, Michael E. (1974). Transportation Geography: Comments and Readings. New York: McGraw-Hill.

Council on Aging (COA) Ottawa (2004). Fact Book on Aging 2004: Seniors in the New Ottawa. Ottawa: Council on Aging Ottawa. (www.coaottawa.ca)

Crane, R. (1996). 'Cars and Drivers in the New Suburbs,' Journal of the American Planning Association 62(1): 51- 64.

Cumming, E. and W. Henry (1961). Growing Old. New York: Basic Books.

Cvitkovich, Y. and A. Wister (2001). "The importance of transportation and prioritization of environmental needs to sustain well-being among older adults," Environment and Behaviour 33(6): 809 - 829.

Dear, M. and S. Flusty (1998). "Postmodern Urbanism," Annals of the American Geographers 88(1): 50-72.

Diener, E. (2000). "Subjective well-being. The science of happiness and a proposal for a national index," American Psychologist 55(1): 34 - 43.

Docherty, I., J. Shaw and M. Gather (2004). "State intervention in contemporary transport," Journal of Transport Geography 12(4): 257-264. 
Duany, A., E. Plater-Zyberk and J. Speck (2000). Suburban Nation: The rise of sprawl and decline of the American Dream, New York: North Point Press.

Dulude, Louise. (1981). Pension Reforms with Women in Mind. Ottawa: Canadian Advisory Council on the Status of Women.

Hurst, Michael E. (1974). Transportation Geography: Comments and Readings. New York: McGraw-Hill.

Estes, Carroll L. (1979). The aging enterprise. San Francisco: Jossey-Bass.

---- (1981). "The new political economy of aging: Introduction and critique" In: M. Minkler and C. L. Estes (Eds) Critical perspectives on aging: The political and moral economy of growing old. Amityville, NY: Baywood.

----- (2001). Social Policy and Aging: A Critical Perspective. Thousand Oaks, California: Sage Publications.

Farrington, John and Conon Farrington (2005). "Rural accessibility, social inclusion and social justice: Towards conceptualization". Journal of Transport Geography 13: 112.

Fern, Edward F. (2001). Advanced focus group research. Thousand Oaks, California: Sage Publications.

Fujii, S. and R. Kitamura (2003). 'What does a one month free bus ticket do to habitual drivers,' Transportation 30:81-95.

Gaber, S. L. and J. Gaber (1999). "Qualitative assessment of transit needs: The Nebraska case" Journal of Urban Planning and Development 125(2): 59-67.

George, Linda K. and Lucille B. Bearon (1980). Quality of life in older persons: meaning and measurement. New York: Human Sciences Press.

Giersch, H. (Ed.) (1995). Urban agglomeration and Economic Growth. Berlin: Springer

Giuliano, G. (1989). 'New Directions for Understanding Transportation and Land Use,' Environment and Planning A 21:145-159.

Giuliano, G. and K.A. Small (1995). 'Alternative Strategies for Coping with Traffic Congestion,' In: Giersch, H. (Ed.) Urban agglomeration and Economic Growth. Berlin: Springer. pp.199-225. 
Golant, S.M. (1986a). "Subjective housing assessments by the elderly: a critical information source for planning and program evaluation," The Gerontologist 26: 122-127.

---- (1986b). "The suitability of old people's residential environments: Insights from geographic literature," Urban Geography 7(5):437 - 447.

---- (1992). “The suburbanization of the American elderly,” In: Rogers, Andrei, William H. Frey, Philip Rees, Anthony Spear Jr., and Alden Warnes, (Eds). Elderly Migration and Population Redistribution: A Comparative Study. London, UK: Belhaven Press. pp.163 - 180.

Goldsmith, William M. (1996). "From the metropolis to globalization: The dialiectics of race and urban form," In Fainstein, Susan S. and Scott Campbell (Eds). Readings in Urban Theory, Malden Massachusetts: Blackwell.

Gomez-Ibanez, Tye and Winston (Ed.) (1999). Essays in Transportation Economics and Policy, Washington D.C: Brookings.

Goss, J.D. (1996). “Introduction to focus groups,” Area 28(2):113-114.

Greene, D.L. and M. Wegener (1997). "Sustainable Transport," Journal of Transport Geography, 5(3): 177-190.

Hanlon, N. and G. Halseth (2005). "The graying of resource communities in northern British Columbia: Implications for health care delivery in already underserviced communities," Canadian Geographer, 49(1): 1-24.

Hanson, S. (1986). The Geography of Urban Transportation. New York: Guilford Press.

Harris, C.D. and E.L. Ullman (1959). "The nature of cities”, In: Mayer, H.M. and C. Kohn (Eds.) Readings in Urban Geography, Chicago: Chicago Press.

Harvey, D. (1969). Explanation in Geography, London: Edward Arnold.

(1984). 'On the history and present condition of geography: An historical materialist manifesto,' Professional Geographer, 36:1-11.

----- (1985). The Urbanization of Capital, Baltimore: John Hopkins Press.

Havighurst, R.J. (1968). Personality patterns of aging. The Gerontologist 8(1) Spring, Part II: $20-23$. 
Haynes, K.E., J.L. Gifford, and D. Pelletiere. (2005). "Sustainable transportation institutions and regional evolution: global and local perspectives," Journal of Transport Geography, 13(3): 207-221.

Hayward, Lynda, and Michael Lazarowich (1998). "A Resting Development," Plan Canada, July: 15-18.

Health and Welfare Canada (1982). Canadian Governmental Report on Aging. Ottawa: Health and Welfare Canada.

Health Canada (2002). Canada's aging population: a report prepared by Health Canada in Collaboration with the Interdepartmental Committee on Aging and Seniors Issues. Ottawa: Health Canada.

Hoggart, Keith, Loretta Lees and Anna Davies (2002). Researching Human Geography. New York: Oxford University Press Inc.

Hoyt, Homer (1939). The structure and growth of residential neighbourhoods in American Cities. Washington D.C.: Federal Housing Administration.

Jackson, Peter (2001). "Making sense of Qualitative Data," In: Limb, Melanie and Claire Dwyer Qualitative methodologies for geographers: Issues and debates. New York: Oxford University Press: 199 - 214.

James, Preston E. and Clarence F. Jones (Eds.) (1954). American Geography: Inventory and Prospect. American Association of Geographers, Syracuse University Press.

Jensen, M. (1999). "Passion and heart in transport - a sociological analysis on transport behaviour," Transport Policy 6(1): 19-33.

Kaufmann, V. (2002). "The rationality of perception and modal choice: Is quickest best?" Recherche - Transports - Securite 75:131-143.

Kenyon, Susan, Glenn Lyons and Jackie Rafferty (2002). "Transport and social exclusion: investigating the possibility of promoting inclusion through virtual mobility," Journal of Transport Geography 10: 207-219.

Kitchin, Rob and Nicholas J. Tate (2000). Conducting research into human geography: Theory, methodology and practice. Harlow: Prentice Hall.

Kuypers, J.A. and V.L. Bengston (1973). "Social breakdown and competence," Human Development 16: $181-201$. 
Laczko, Frank and Christina R. Victor (1992). Social Policy and Elderly People. Aldershot England: Avebury.

Law, M., K. Wilson, J. Eyles, S. Elliott, M. Jerrett, T. Moffat, and I. Luginaah (2005). "Meeting health need, accessing health care: The role of neighbourhood," Health and Place 11(4): 367-377.

Lawton, M.P. (1983). "Environment and other determinants of well-being in older people," The Gerontologist 23: 249 - 357.

----- (1991). "Quality of life: Medical and other." In J.E. Birren, D.E. Deutchman, J.Lubben \& J. Rowe (Eds.) The concept and measurement of quality of life in the later years. New York: Academic Press.

Levy, Sidney J. (1979). "Focus group interviewing," In: James B. Higginbotham and Keith K. Cox (eds.) Focus Group Interviews: A reader. Chicago: American Marketing Association: 34-42

MacQuarrie, M. and B. Keddy (1992). "Women and Aging: Directions for research," Journal of Women and Aging, 4(2): 21-32.

Marble, D.F. (1967) “A Theoretical exploration of individual travel behaviour," In: Garrison, W.L. and D.F. Marble (Eds.) Quantitative Geography Part 1. Evanston: Northwestern University: 33-53.

Matcha, Duane A. (1997). The Sociology of Aging: A Social Problems Perspective. Boston: Allyn and Bacon.

Maurier, Wendy L. and Herbert C. Northcott (2000). Aging in Ontario: Diversity in the New Millennium. Calgary: Detselig Enterprises Ltd.

McCracken, G. (1988). The long interview. Newbury Park, California: Sage Publications.

McDaniel, Susan A. (1986). Canada's Aging Population. Toronto and Vancouver: Butterworths.

McPherson, Barry D. (1998). Aging as a Social Process: An introduction to individual and population aging. Toronto: Harcourt Brace.

Morgan, David L. (1988). Focus groups as qualitative research. Newbury Park, California: Sage Publications. 
---- (1997). Focus groups as qualitative research, $2^{\text {nd }}$ Ed. Newbury Park, California: Sage Publications.

(1998a). The focus group kit: Planning focus groups. Thousand Oaks, California: Sage Publications.

---- (1998b). The focus group kit: The focus group guidebook. Thousand Oaks, California: Sage Publications.

Morgan, David L. and Richard A. Krueger (1993). "When to use focus groups and why," In: Morgan, David L. (Ed.). Successful focus groups: Advancing the state of the art. Newbury Park, California: Sage Publications

National Advisory Council on Aging (1992). The NACA Position on Canada's Oldest Seniors: Maintaining the quality of their lives. Ottawa.

---- (1999). Challenges of an Aging Canadian Society. Ottawa.

Newbold, K. B., D.M. Scott, J.E.L. Spinney, P. Kanaroglou, and A. Paez (2004). "Travel behavior within Canada's older population: a cohort analysis," Journal of Transport Geography, Article in press.

Newman, P.W.G. and J.R. Kenworthy (1996). 'The land use-transport connection,' Land Use Policy, 13(1): 1-22.

Pargal, S. and M. Heil (2000). 'Reducing Air Pollution from Urban Passenger Transport: A framework for policy analysis,' Journal of Environment and Planning Management, 43(5): 665-668.

Parsons, J.J. (1969). “Towards a more humane geography,” Economic Geography, 45(3): i.

Pas, Eric I. (1986) "Chapter 3: The Urban Transportation Planning Process.” In: Hanson, S. (Ed.). The geography of urban transportation. New York: Guilford Press: 4970.

Poortinga, W., L. Steg and C. Vlek (2004). "Values, environmental concern and environmental behaviour: a study into household energy use," Environment and Behaviour 36(1): 70-93.

Randall, Todd A. and Brian W Baetz. (2001). "Evaluating pedestrian connectivity for suburban sustainability," Journal of Urban Planning and Development 127(1): 115. 
Rose, A.M. (1965). "The subculture of aging: A framework for research in social gerontology," In: A.M. Rose and W.A. Peterson (Eds.) Older people and their social world. Philadelphia: F.A. Davis.

Rosenberg, M. and J. Everitt. (2001). "Planning for aging populations: inside or outside the walls," Progress in Planning 56: 119-168.

Rosenberg, M. and E.G. Moore (1990). "The elderly, economic dependency, and local government revenues and expenditure". Environment and Planning C: Government and Policy 8: 149 - 165.

Rosenbloom, S. (2001). "Sustainability and automobility among the elderly: An international assessment," Transportation 28(4): 375-408.

Rosenbloom, S., and J. Morris (1998). "The travel patterns of older Australians in an international context; policy implications and options," Transportation Research Record 1617: 91.

Schultzman, A. (1992). "Public transportation in the $20^{\text {th }}$ century" In: Grey, George and Lester Hoel (Eds.) Public Transportation. Englewood Cliffs, New Jersey: Prentice Hall: 24-39.

Shoup, D. (1999). "The trouble with minimum parking requirements," Transportation Research Part A, 33: 549-574.

Shriver, K. (1997). "Influence of environmental design on pedestrian travel in four Austin neighbourhoods," Transportation Research Record 1578: 64-75

Small, K.A. (1992). Urban Transportation Economics. Chur: Harwood Academic Press.

----- (1997). "Economics and urban transportation policy in the United States," Regional Science and Urban Economics, 27:671-691.

Statistics Canada (2001). Population Projections for Canada, Provinces and Territories 2000 - 2026, Catalogue No. 91-520.

Steg, L., and R. Gifford (2005). "Sustainable Transportation and Quality of Life," Journal of Transport Geography 13: $59-69$.

Stewart, Anita L. and Abby C. King (1994) "Quality of life determinants in Older Adults,” In: Abeles, Ronald P., Helen C. Gift, and Marcia G. Ory (1994). Aging and Quality of Life. New York: Springer Publishing Co. 
Stewart, David W. and Prem N. Shamdasani (1990). Focus Groups: Theory and practice. Newbury Park, California: Sage Publications.

Taaffe, E.J., H.L. Gauthier and M.E. O'Kelly (1996). Geography of Transportation, $2^{\text {nd }}$ Ed. Upper Saddle River, New Jersey: Prentice Hall.

Taylor, Susan. (1998). "Retirement Planning," Plan Canada, July: 12-14.

Ullman, Edward L. and Harold M. Mayer (1954). "Chapter 13: Transportation Geography," In: James, Preston. E. and Clarence F. Jones, American Geography: Inventory and Prospect. American Association of Geographers, Syracuse University Press.

Ullman, E.L. (1973). “Geography as spatial interaction,” In: Hurst, Michael E. (1974). Transportation Geography: Comments and Readings. New York: McGraw-Hill: $29-40$.

Waterton, Claire and Brian Wynne (1999). "Can focus groups access community views?" In: Barbour, Rosaline S. and Jenny Kitzinger (Eds.). Developing Focus Group Research: Politics, theory and practice. Thousand Oaks California: Sage Publications: $127-143$.

Winchester, Hilary P.M. (2000). "Qualitative research and its place in human geography," In: Hay, Iain. Qualitative research methods in human geography. South Melbourne, Victoria: Oxford University Press.

Winter, Michael A. and Fred Laurence Williams (2001). "Transit access for Americans: A proposal for the next stage of implementing the Americans with Disabilities Act of 1990," Policy Studies Journal, 29(4): 674 - 681.

Woodward, C.A. J. Abelson, S. Tedford and B. Hutchinson (2004). "What is important to continuity in home care? Perspectives of key stakeholders," Social Science and Medicine, 58(1): 177-192. 